\title{
The Regime-Switching Behaviour of Exchange Rates and Frontier Stock Market Prices in Sub-Saharan Africa
}

\author{
Maud Korley and Evangelos Giouvris *D
}

Citation: Korley, Maud, and Evangelos Giouvris. 2021. The Regime-Switching Behaviour of Exchange Rates and Frontier Stock Market Prices in Sub-Saharan Africa. Journal of Risk and Financial Management 14: 122. https:// doi.org/10.3390/jrfm14030122

Academic Editor: Gilbert Nartea

Received: 4 February 2021

Accepted: 8 March 2021

Published: 15 March 2021

Publisher's Note: MDPI stays neutral with regard to jurisdictional claims in published maps and institutional affiliations.

Copyright: (c) 2021 by the authors. Licensee MDPI, Basel, Switzerland. This article is an open access article distributed under the terms and conditions of the Creative Commons Attribution (CC BY) license (https:/ / creativecommons.org/licenses/by/ $4.0 /$ )
School of Business and Management, Royal Holloway, University of London, Egham TW20 0EX, UK; maud.korley.2018@live.rhul.ac.uk

* Correspondence: evangelos.giouvris@rhul.ac.uk

\begin{abstract}
Frontier markets have become increasingly investible, providing diversification opportunities; however, there is very little research (with conflicting results) on the relationship between Foreign Exchange (FX) and frontier stock markets. Understanding this relationship is important for both international investor and policymakers. The Markov-switching Vector Auto Regressive (VAR) model is used to examine the relationship between FX and frontier stock markets. There are two distinct regimes in both the frontier stock market and the FX market: a low-volatility and a high-volatility regime. In contrast with emerging markets characterised by "high volatility/low return", frontier stock markets provide high (positive) returns in the high-volatility regime. The high-volatility regime is less persistent than the low-volatility regime, contrary to conventional wisdom. The Markov Switching VAR model indicates that the relationship between the FX market and the stock market is regime-dependent. Changes in the stock market have a significant impact on the FX market during both normal (calm) and crisis (turbulent) periods. However, the reverse effect is weak or nonexistent. The stock-oriented model is the prevalent model for Sub-Saharan African (SSA) countries. Irrespective of the regime, there is no relationship between the stock market and the FX market in Cote d'Ivoire. Our results are robust in model selection and degree of comovement.
\end{abstract}

Keywords: foreign exchange market; stock market; frontier countries; Markov-switching VAR

JEL Classification: C22; C24; F31; G15

\section{Introduction}

Economic uncertainties, technological advancements, and globalization have made countries vulnerable to volatility (Eissa et al. 2010). As a result, several studies have investigated interdependencies between financial markets, identified through changes in stock prices, exchange rates, or capital flows (Tsai 2012; Tsagkanos and Siriopoulos 2013). Studies on interdependencies are important because they have direct implications on how information is transferred between financial markets and several practical implications to investors and policymakers (Tsagkanos and Siriopoulos 2013). Recently, studies such as Caporale et al. (2014) emphasised the interdependencies between foreign exchange and stock markets. This may partly be explained on one hand by the occurrence of several financial crisis, such as the US subprime crisis in 2007, characterised by a sharp drop in asset prices that severely affected the foreign-exchange market with large losses in international portfolios (Walid et al. 2011; Caporale et al. 2014) On the other hand, practical concerns of policymakers and questions left unanswered from theoretical models have motivated empirical studies on interdependencies between foreign exchange and stock markets (Eissa et al. 2010).

Literature has provided two potential theories that are useful for understanding interdependencies between foreign exchange and stock markets. These are (i) the traditional approach based on the flow-oriented model (Dornbusch and Fischer 1980) and (ii) the portfolio-balance effect based on the stock-oriented model (Branson 1983). The 
flow-oriented model states that movement in exchange rates has an impact on the net worth of firms. This is because firms borrow in foreign currencies, which affects their competitiveness and earnings, and hence their stock prices (Chkili and Nguyen 2014). Unexpected changes in exchange rate expose the economic value of firms to exchange-rate risk that is likely to influence the export/import sales of these firms and consequently, their stock price. This theory supports a directional impact from changes in exchange rates on stock prices, with claims that stock prices and exchange rates should be positively related (Walid et al. 2011). In support of the flow-oriented approach, studies such as Roll (1992); Chortareas et al. (2011); and Caporale et al. (2014), found a positive relationship between exchange rates and stock-market prices.

The stock-oriented model assumes a supply-and-demand mechanism in that the performance of the stock market may either increase or reduce capital inflows from foreign investors. Changes in stock prices may affect demand for a country's currency, causing exchange rates to appreciate or depreciate, as causality runs from the stock market to foreign exchange (FX) market (Tsai 2012; Caporale et al. 2014). For example, an increase in stock price, ceteris paribus, increases return on investment. This could in turn increase demand for a country's currency (if investors decide to invest in this country because of higher returns), consequently leading to appreciation of the local currency. Similarly, a fall in stock prices will reduce return on investment, which could reduce demand for a country's currency as investors sell their stocks, causing a depreciation of the local currency. Contrary to the flow-oriented model, stock and FX markets should be negatively correlated. Studies such as Hatemi-J and Irandoust (2002) and Tsai (2012) are in support of the stock-oriented approach.

Empirically, there are several studies on interdependencies between exchange rates and stock prices (Tsai 2012; Tsagkanos and Siriopoulos 2013). However, the focus is on the advantage and leverage of developed and emerging stock markets, while less attention is given to frontier markets, particularly in Africa. Frontier markets (See FTSE Russell (2014) for classification and discussion of frontier markets) differ from emerging markets in terms of size, liquidity, and risk (Eissa et al. 2010). Recently, frontier markets have become increasingly investible, as they offer low correlation among assets with increased growth opportunities and diversification benefits, and therefore are an interesting niche for researchers to provide further insights (Ntim 2012). This has become a challenge to the once-favoured emerging markets, which over the years are becoming closely correlated with developed markets, and pose major challenges for investors (FTSE Russell 2014) in seeking consensus among findings

In this study, our focus is on frontier stock markets in sub-Saharan Africa (SSA). We focus on Africa for two reasons. First, there is a dearth of detailed studies on the relationship between FX and the frontier market in Africa. Policymakers in Africa are unsure what interventions to put in place, as researchers seem to have focused on seeking consensus among findings in developed and some Asian countries. While useful, the applicability of these findings to frontier markets in Africa is questionable. Second, these countries are showing increasing economic growth and promising performance in the global market. For example, some African countries experienced increasing economic growth from 2009. Specifically, in 2014, Africa's GDP grew by 3.9\% compared to 3.3\% globally, indicating increasing economic growth amidst a fall in commodity prices, with growth projected to increase by $4.3 \%$ in 2018 . In the same period, foreign direct investment was projected to USD 57 billion due to increasing Greenfield investment from emerging countries such as China. Accordingly, with the potential to grow faster globally and the continuous improvement in economic growth, investor confidence in Africa has increased (AfDB, OECD, UNDP; African economic outlook 2015 (AfDB et al. 2015)).

In addition to the points already raised, unravelling the relationship between exchange rates and stock prices is important, as such studies may be invaluable to influence the financial decisions of multinational organisations operating in Africa. These organisations need to understand the relationship between stock prices and exchange rates to manage 
their exchange rate exposure (Eissa et al. 2010). Thus, to inform future interventions, it is useful for frontier markets in SSA to have access to their own empirical evidence in relation to the linkages between FX and stock market to develop the needed regulatory framework to attract foreign investors.

There are alternative conversations on the comovement between exchange rates and frontier markets in SSA. For example, Adjasi et al. (2008) showed that a depreciation in the local currency leads to an increase in stock-market returns in Ghana. However, Adjasi et al. (2011) found no relationship between the exchange rate and the stock market in Ghana. In another study, Kodongo and Ojah (2011) assert that stock markets in SSA are moderately segmented from exchange-rate shocks, and that investors can invest across these markets without bothering about exchange-rate risk. These studies predominantly relied on linear models and ignored the likelihood that the relationship between exchange rates and stock prices may vary due to structural changes and/or regime shifts. Phylaktis and Ravazzolo (2005) demonstrated that structural changes in both variables may have an influence on the relationship between exchange rates and stock prices. Also, empirical evidence shows that financial and macroeconomic variables are nonlinear and subject to regime changes (Balcilar et al. 2015). Indeed, Diebold and Yilmaz (2009) confirmed that shock spillover intensities across markets are time-varying. However, the linear approach lacks the ability to capture the time-varying nature of volatility and other events due to occasional shifts in the markets.

In this paper, we attempt to revisit the relationship between exchange rates and frontier markets for five countries in SSA; namely, Côte d'Ivoire, Ghana, Kenya, Mauritius, and Nigeria, using weekly data from January 2000-December 2018. From an empirical standpoint, this study proposes to shed light on the assertions underlying the relationship between the two variables in SSA and extend the studies of Kodongo and Ojah (2011) and Adjasi et al. (2011) by employing a nonlinear approach, the Markov-switching (MS) model. The MS model has the ability to accurately track movement in economic time series and capture sudden dramatic changes that do not rely on ad hoc determination of the crisis period (Pericoli and Sbracia 2003). Besides, in the period under investigation, the stock and FX market experienced dramatic events such as the " $9 / 11$ " terrorist attacks, the global financial crisis in 2008, and the oil shocks in 2016. Specifically, the global financial crisis has been noted by experts to have had significant negative impacts on stock returns and exchange-rate volatility (Walid et al. 2011; Caporale et al. 2014) due to increased capitalmarket integration and interdependency of the global stock market (Lim and Giouvris 2015). Bleaney and Greenaway (2001) stated that with the advent of increasing globalisation and full integration of the world market, frontier markets in Africa seem not to be an exception to the global financial crisis, as these countries heavily depend on exports of primary commodities and foreign trade. In this regard, we try to identify if the relationship between exchange rates and frontier stock prices for the five countries in SSA is subject to different regimes. In a related study on developed stock markets, Wang et al. (2013) posited that the comovement between exchange rates and stock prices is higher during turbulent times than in calm periods. Walid et al. (2011) reported the same for emerging stock markets and revealed the presence of two distinct regimes; a low-volatility/high-return regime and a high-volatility/low-return regime. Both Wang et al. (2013) and Walid et al. (2011) are of the view that the relationship between the two variables is subject to regime changes.

Our main objectives are twofold: first, to examine the existence of regime-switching behaviour in the stock market and FX market, allowing the mean and variance to switch across different regimes; and second, to investigate the existence of regime-switching behaviour in the relationship between exchange-rate changes and returns of frontier stock markets. This study therefore answers the following questions:

RQ1: Is there any regime-switching behaviour in volatility in both the stock market and FX market in Cote d'Ivoire, Ghana, Kenya, Mauritius, and Nigeria?

RQ2: Is the effect of exchange rates on stock prices in the selected countries regimedependent? 
RQ3: Is the effect of stock prices on exchange rates in the selected countries regimedependent?

By addressing these questions, our study adds to the understanding of volatility interdependencies between exchange rates and stock prices and corrects the methodological issues previously identified. The findings from our study have direct implications for financial hedging, portfolio management, and asset allocation, specifically for fund managers who seek to hedge their investment in frontier markets to make informed decisions in the short run. Our findings will also inform policy decisions, as they seek to focus on developing optimal strategies, especially during crises, to increase stock-market stability as well as design a suitable framework for foreign-exchange management to stabilize the currency.

Our paper differs from other studies in the following ways. First, while previous empirical studies on the link between exchange rates and stock prices are mainly on developed markets and some Asian countries, our interest is on frontier markets in SSA. Previous studies on SSA, however, have focused on how stock prices respond to the exchange-rate shocks. We examine the bidirectional relationship between exchange rates and stock prices. Second, from a methodological point of view, instead of modelling the relationship as a linear VAR, we employed the MS model. The model allows us to capture the different regimes; hence, we attempt to determine the degree and timing of comovement. To the best of our knowledge, this is the first empirical study of interdependencies between exchange rates and stock prices in frontier countries in Africa to adopt the MS model. This study further evaluates the nonlinear properties of the MS-VAR and MS-VECM models. Third, unlike most studies, we determine the regime-shift behaviour, both in the mean and the variance, not only in the frontier stock market but also in the exchange-rate market. In addition, we present a recent picture on the relationship between exchange rates and frontier markets by using a more recent sample period of 2000-2018. Finally, we also conduct detailed sensitivity analysis of the results with respect to alternative sample periods and alternative techniques.

The results of this paper demonstrate that the frontier markets are characterised by two distinct regimes: the high-volatility regime, which is associated with high returns, and the low-volatility regime, which is associated with low returns. We find that the high-volatility regime is less persistent compared to the low-volatility regime. With regard to the regime causality, we find that the effect of stock prices on exchange rate is negative; however, in Kenya and Mauritius, this is observed only during the low-volatility regime. There is not much evidence of a reverse effect; although positive, it was not significant for most countries. Hence, we conclude that the stock-oriented model is more prevalent than the reverse effect. Our results are robust in alternative techniques (quantile regression) as well as different subsample periods (precrisis and postcrisis periods).

The rest of the study is organised as follows: Section 2 presents a brief overview of the frontier markets, and previous empirical evidence on the relationship between stock prices and exchange rates, including relevant literature on the regime-switching model. Section 3 explains the research methodology, including details of the econometric model adopted, while Section 4 outlines the results of the statistical test analysis and the outcome of the econometric model. Finally, Section 5 provides the conclusions of this study.

\section{Literature Review}

\subsection{Overview of Frontier Markets}

Frontier markets, according to FTSE Russell (2014), show characteristics such as "openness to foreign ownership" and "ease of capital flow" that warrant their inclusion in a global portfolio. Of the 19 stock exchanges in Sub-Saharan Africa, six have been classified by FTSE as frontier markets. These are Botswana, Cote d'Ivoire, Ghana, Kenya, Mauritius, and Nigeria (FTSE Russell 2014). Each of the markets have shown considerable positive performance over the years. For example, in Ghana, the total market capitalization in 2017 
was GHS 52690.99 million. This represented an increase of $11.48 \%$ from the previous year (SEC 2017).

Frontier markets recently have attracted the attention of investors due to their potential for growth and diversification benefits (Ntim 2012; FTSE Russell 2014). These markets therefore warrant their own empirical studies, as they are small and less liquid compared to emerging markets. For example, the combined worth of the frontier markets is USD 715 billion, while that of the emerging markets is USD 20 trillion (Bloomberg 2019). As shown in Table 1, the average number of listed companies ranges from 35 to 190, compared to over 300 listed companies in emerging markets (South Africa/Brazil/India/China). Similarly, the equity market capitalisation in these frontier markets on average is USD 10 billion, in contrast to USD 400 billion in emerging markets. With regard to liquidity, the average value of stocks traded in the frontier markets ranges between USD 400 million and USD 5 billion, whilst that of the emerging countries is between USD 230 billion and USD 70 trillion. Therefore, with the outlined differences, there is the need for more research focus on the frontier markets.

Table 1. Frontier vs. emerging markets.

\begin{tabular}{cccc}
\hline Country & $\begin{array}{c}\text { Number of Listed } \\
\text { Companies }\end{array}$ & $\begin{array}{c}\text { Total Market Capitalization } \\
\text { (USD Million) }\end{array}$ & $\begin{array}{c}\text { Total Equity Market Value } \\
\text { Traded (USD Million) }\end{array}$ \\
\hline Frontier & & & 521.85 \\
Cote d'Ivoire & 39 & $12,493.03$ & 619.10 \\
Ghana & 39 & 1427.92 & 683.05 \\
Kenya & 64 & $20,429.38$ & 460.79 \\
Mauritius & 72 & 7238.55 & 4084.89 \\
Nigeria & 184 & $49,973.88$ & \\
\hline Emerging & & & $233,988.40$ \\
South Africa & 382 & $735,945.17$ & $419,977.77$ \\
Brazil & 359 & $490,543.11$ & $65,519,901.00$ \\
India & 1749 & $1,485,088.6$ & $20,475,060.70$ \\
China & 1081 & $4,602,106.89$ & \\
\hline
\end{tabular}

Source: World Bank.

\subsection{Theoretical Background}

In this section, we discuss the possibility of interdependencies between the stock and exchange-rate markets. There is an increased focus by scholars and practitioners on the relationship between exchange rates and stock prices. This may be partly explained by the fact that in recent times, globalization has led to few to little barriers to the flow of investment opportunities across countries (Kutty 2010). Theoretical arguments from studies such as Dornbusch and Fischer (1980) documented the relationship between stock prices and exchange rates; however, the empirical evidence regarding them is still mixed. The theoretical approaches mentioned earlier, the traditional approach and the portfolio-balance effect, are based on the flow-oriented model and the stock-oriented model, respectively.

In line with the traditional approach, Ma and Kao (1990) pointed out that exchangerate depreciation (domestic-currency appreciation) usually reduces the competitiveness of export markets and generates a negative impact on their stock prices, hence a negative effect for export-dominant countries. Equally, exchange-rate depreciation has a positive effect on import-dominated countries, as it reduces import costs and generates a positive impact on the stock market. In his work, Roll (1992) used a sample from 24 countries for the period 1988-1991 and observed a positive relationship between exchange rates and stock prices. Chortareas et al. (2011) investigated the link between stock prices and exchange rates using the Johansen cointegration test and showed that exchange rates have positive impacts on stock prices in Egypt and Oman. Caporale et al. (2014) recently investigated the link between exchange rates and stock prices by employing the bivariate UEDCC-GARCH models on weekly data covering the period from 2007 to 2010 for six advanced economies (namely, the USA, the UK, Canada, Japan, the Euro area, and Switzerland). The authors 
found a unidirectional Granger causality from exchange-rate changes to stock returns in Canada.

On the contrary, in agreement with the stock-oriented approach, a study by Hatemi-J and Irandoust (2002) showed a unidirectional relationship from stock prices to exchange rates in analysing monthly data over a period of five years from Sweden. Tsai (2012) adopted the quantile regression in analysing the relationship between stock prices and exchange rates for six Asian countries, and the results showed that the stock prices took the lead and had a negative impact on exchange rates for all markets.

The stock-oriented approach proposes that a vibrant and attractive stock market will attract more foreign capital and thereby cause an appreciation of the domestic currency. Considering studies showing that frontier markets are increasingly attractive to investors (Ntim 2012; FTSE Russell 2014), we expect the portfolio-balance effect mentioned by Branson (1983) to therefore exist in these markets. However, as argued by Phylaktis and Ravazzolo (2005), structural changes in the data may have an influence on the relationship that exists between the two variables. Correspondingly, in this study we made efforts to account for the structural changes inherent in the period examined using the MS model.

\section{Empirical Evidence}

In this subsection, we briefly review a number of articles on the relationship between exchange rates and stock prices from G7 (developed), Asian (emerging), and African (developing) countries that have employed different methodologies. While empirical methodologies vary widely, these studies have predominantly relied on linear models and have assumed a linear relationship between the two variables over the sample period.

\section{Developed Countries}

Existing studies on the relationship between exchange rates and stock prices have mostly focused on developed economies, such as the UK, the USA, Germany, and Canada. For example, a study by Hwang (1999) testing the relationship between the Canadian dollar and the prices of stocks listed on the Toronto Stock Exchange from 1973 to 1996 using an Engle-Granger cointegration test found no long-run relationship between exchange rates and stock prices. However, the exchange rate had a positive effect on stock price only in the short run. Chow et al. (1997), in their work, employed regression analysis to examine the relationship between exchange rates and stock prices for the USA. The study concluded that there was a statistically significant positive relationship between exchange rates and stock prices. In contrast, Tsagkanos and Siriopoulos (2013) reported a significant negative relationship between the variables in examining the long-run relationship between exchange rates and the stock prices for the USA and European Union (EU) for the period 2008-2012 using a nonparametric cointegrating approach.

Kanas (2000), in another study using EGARCH, found evidence of volatility spillovers from stock returns to exchange-rate changes for the UK, the USA, Japan, France, and Canada, but no evidence from exchange-rate changes to stock returns for all countries. In addition, Kanas (2002), while adopting a similar approach to examine the effect of stockmarket volatility on exchange rates for the USA, the UK, and Japan for the period 1986-1998, concluded that the impact of stock-market volatility on exchange rates is positive.

\section{Emerging Countries (Asia)}

Studies on the relationship between exchange rates and stock prices have also mainly focused on the various Asian countries. This further increased after the Asian crisis of 1997 (Bahmani-Oskooee and Saha 2015). In a study, Smyth and Nandha (2003) employed Granger causality and Johansen cointegration tests to examine the relationship between exchange rates and stock prices for a sample of data from India, Pakistan, Bangladesh, and Sri Lanka from 1995 to 2001. The study found no long-run relationship between exchange rates and stock prices. Similarly, Pan et al. (2007), using Granger causality and Johansen cointegration tests, examined the relationship between exchange rates and stock prices 
using a sample from seven Asian countries; namely, Malaysia, Thailand, Taiwan, Japan, Hong Kong, Singapore, and Thailand from 1988 to 1998. They concluded that there was no stable long-run equilibrium relationship between exchange rates and stock prices.

Another study of six Asian countries from 2000 to 2008 by Lee et al. (2011) found a significant relationship between exchange rates and stock prices while using the EGARCH model to examine the relationship between the two variables. Tsai (2012) in another study found a negative relationship between exchange rates and stock prices using data from 1992 to 2009 for a sample of data from six Asian countries using the quantile regression method. The author further reported that the relationship between exchange rates and stock prices depended on market conditions. On the contrary, Phylaktis and Ravazzolo's (2005) study showed a positive link between stock prices and foreign-exchange markets. They employed Johansen cointegration and multivariate Granger causality tests to investigate the dynamic relationship between stock prices and exchange rates in five Asian countries from 1980 to 1998.

\section{Developing Countries (Africa)}

Despite the importance attributed to the effect of interdependencies between exchangerate changes and stock returns, there are few studies on Africa. The studies assumed a linear relationship between the two variables over the sample period. For example, Eissa et al. (2010) analysed volatility interdependencies between exchange-rate changes and stock returns for Egypt and Morocco using the MGARCH model. They found evidence of a volatility-spillover effect from the exchange rates to the stock returns for Egypt, but found no evidence of shocks spillovers from exchange rates to stock returns for Morocco. Tule et al. (2018) tested volatility spillovers between stock-market returns and exchange rates in Nigeria for the period 2007-2016 using the VARMA-AGARCH model, and found a highly significant transmission of shocks from the stock market to the FX market. However, the return spillover from the FX market to the stock market was not statistically significant. Adjasi et al. (2008) also employed the EGARCH model to investigate the relationship between the stock market and FX market for Ghana from 1995 to 2005 . The study concluded that there was a negative relationship between exchange-rate volatility and stock prices. In another study, Adjasi et al. (2011) employed VAR cointegration and impulse-response analysis to examine the relationship between stock prices and exchange-rate movements for a sample of data from the seven African countries of South Africa, Egypt, Tunisia, Nigeria, Ghana, Kenya, and Mauritius during the period 1992-2005. They found no long-run relationship between the stock markets and exchange rates for all sample countries except for Tunisia.

Although these studies do not constitute an exhaustive list, they provide an overview of different methods and findings of studies on the relationship between exchange rates and stock prices in developed, Asian, and some African countries. These studies predominantly relied on linear models and assumed a linear relationship between the two variables over the sample period. Although the linear approach has its own relevance in terms of robustness, assuming a stable and linear relationship may lead to inaccurate findings, as the linear cointegration regression may be biased (Tsagkanos and Siriopoulos 2013) and may also mislead the conclusions about their time-varying behaviour and interactions between stock prices and exchange rates (Chiang et al. 2007). Similarly, Diebold and Yilmaz (2009) showed that spillover intensity across markets varies over time. Therefore, in this study, instead of modelling the relationship between exchange rates and stock prices as a linear VAR, we employed the nonlinear MS model with regime shift in both the mean and the variance to capture and account for the time-varying shock-spillover effect.

\subsection{Further Justification on MS Model}

Theoretically, the relationship between exchange rates and stock prices has different positions. The theories are implicitly based on free-floating exchange-rate arrangement (Lv et al. 2018). The exchange-rate arrangement (See Ilzetzki et al. (2017) for more details 
on the different exchange-rate arrangements adopted for the sampled countries) for the countries under study has evolved over time. The IMF (2016) classifies these countries under the following exchange-rate arrangements: floating exchange rate (Ghana, Kenya, Mauritius), stabilized arrangement (Nigeria), and conventional peg (Cote d'Ivoire). Akram (2004) argued that the exchange-rate arrangement adopted by a country could distort the causality between exchange rates and other financial and economic variables. The IMF (2016) regional economic outlook on sub-Saharan African countries supports Akram's (2004) assertion that the exchange-rate arrangement influences economic outcomes, and therefore, to what extent exchange-rate arrangements in these SSA countries can reduce or eliminate the relationship between exchange rates and stock prices. Lv et al. (2018) posits that the exchange-rate arrangement can affect the behaviour of the nominal exchange rate. These countries have adopted different exchange-rate arrangements over the period examined in an attempt to stabilise their currencies (Ilzetzki et al. 2017). Consequently, these different exchange-rate arrangements may cause structural changes in the period examined. Sarno and Valente (2006) noted that allowing regime shifts in the relationship between exchange rates and relative prices is adequate, since it captures the underlying impact of either fixed or flexible exchange-rate arrangements. Therefore, in this study, using the MS model is appropriate.

\subsection{Evidence on Regime-Switching Approach}

A resurgence of academic interest in regime-switching models is due to their ability to capture potential structural breaks experienced in financial markets and the timing of the shifts due to varied periods of instabilities (Cai 1994). The models also have greater flexibility and perform better at capturing correlation asymmetries reflected in the data (Walid et al. 2011). Additionally, they have gained practitioners' attention as they provide better forecasting than time-invariant linear models in explaining the dynamics of the financial markets, as they capture discrete changes in the data (Chkili and Nguyen 2014).

\subsubsection{Regime-Switching Behaviour in Stock Markets}

Modelling dynamics and asymmetries in economic and financial time series using regime-switching models have become prevalent in diverse ways (Ang and Bekaert 2002). According to Hess (2002) "Markov Switching models, with unobserved regimes, are able to fit these types of stock market behaviour well" (p. 528).

In support of the evidence of a two-state switching behaviour in the stock market, Liu et al. (2012) used Markov-switching models and found that the US stock market switches between two states: a low-return/high-volatility state and a high-return/low-volatility state. Ahmad and Sehgal (2015) employed a MS model to identify regime shift both in mean and variance for seven emerging countries during the period 1996-2012, and found that all the stock markets were characterised by two regimes, i.e., bear and bull markets. Employing a similar approach, Ismail and Isa (2008) provided evidence that an MS model was able to successfully capture the various timing of the regime shifts in the return series for Malaysia, Singapore, and Thailand. They identified two regimes; a high-volatility/lowmean regime and a low-volatility/high-mean regime. Similarly, Walid et al. (2011) provide evidence of two distinct regimes in the stock market of four emerging markets (Hong Kong, Singapore, Malaysia, and Mexico). Their results showed that a high-volatility regime corresponds to a low return; likewise, a low-volatility regime corresponds to a high return.

\subsubsection{Regime-Switching Behaviour in Foreign Exchange Markets}

With regard to regime-switching behaviour in foreign-exchange markets, Engle and Hamilton (1990) were the first to study whether the exchange-rate market exhibits a regimeswitching behaviour. The authors employed a Markov-switching autoregressive (MS-AR) model to investigate changes in exchange rates, and concluded that a Markov-switching model provides a good approximation of the exchange-rate series. Engel (1994) further extended the work of Engle and Hamilton (1990) and reported that Markov-switching 
models are better forecasting models in predicting the movement of the FX markets. According to Bailliu and King (2005), forecasting exchange-rate changes can be improved when modelled as nonlinear. Similarly, Parikakis and Merika (2009) observed that using MS models captures the volatility dynamics in exchange rates, and provides evidence that volatilities are not constant, but alternate between two regimes, which they interpreted as high- and low-volatility periods. Other studies that also applied the MS model to identify and capture nonlinearity and asymmetric behaviour in changes in exchange rates include Bergman and Hansson (2005) and Ismail and Isa (2007).

\subsubsection{Regime-Switching between Exchange Rates and Stock Prices}

Generally, a Markov-switching model allows the variance of stock returns and exchange rates to switch across regimes, with the possibility to capture regime shifts between the variables in the data-generating process (Walid et al. 2011).

On establishing the relationship between stock prices and exchanges rates, Wang et al. (2013) used a dependence-switching copula approach to examine the interdependencies between FX and stock markets for six developed countries: Canada, France, Germany, Japan, Italy, and the UK. Their results indicated the relationship between the two financial markets switches between two regimes, bear and bull markets, with each regime associated with currency depreciation and appreciation. Walid et al. (2011) employed Markovswitching EGARCH to investigate the regime-switching behaviour for four emerging countries (Hong Kong, Singapore, Malaysia, and Mexico) over the period 1994-2009. The study provided strong evidence of regime-switching behaviour in volatility in the emerging stock markets. They concluded that there are two regimes for all sample markets, and the relationship between FX and stock markets is regime-dependent. Li and Chiang (2017) examined the relationship between currency values and the stock returns across nine countries during the 1997 Asian crisis using a regime-switching GARCH approach, and they identified two regimes for all countries: a low-volatility regime and a high-volatility regime, with the former regime being more persistent.

Another study by Chkili and Nguyen (2014) analysed the dynamic relationship between exchange rates and stock prices for BRICS countries during the period 1997-2013. Using the MS-VAR model, they provided evidence of two distinct regimes in the stock markets. They further reported that responses of stock-market volatility to shocks in FX markets were significant in all countries except South Africa. Kanas (2005) employed an MS-VAR model to analyse regime linkages between the Mexican currency market and six emerging markets, and concluded that the relationship between the Mexican currency and stock market is regime-dependent. Recently, Roubaud and Arouri (2018) adopted a similar approach to examine interactions between oil prices, stock returns, and exchange rates, and found significant interactions between the stock and exchange-rate markets. However, they added that the relationship between financial markets was nonlinear and ae regime-dependent, with the relationship being stronger during high-volatility periods.

\section{Research Methodology}

\subsection{Data}

The data series consists of price indices (The BVRM, GSE all share index, NSE20, SEMDEX all share index, and NGSE all share index are used for the stock price index in Cote d'Ivoire, Ghana, Kenya, Mauritius and Nigeria respectively) and nominal exchange rates in Cote D'Ivoire, Ghana, Kenya, Mauritius, and Nigeria. The stock-price index and nominal exchange rates are from Data Stream and Thompson Reuters, respectively. The stock price index retrieved is denominated in local currencies, and nominal exchange rates are expressed in local currencies relative to the United States dollar (USD). The period of study is from 14 January 2000 to 28 December 2018 (990 weekly observations). To reduce the level of noise in using daily data and to better capture the changes that could affect the two variables, we used weekly data. Moreover, according to Wang and Theobald (2008), a higher frequency, such as daily data, makes it difficult to isolate cyclical variations and 
obscures the switching states. The use of weekly data is important in detecting spillover and comovement between financial and economic variables, as suggested by Gallo and Otranto (2008). Weekly data have been used by other studies in detecting spillover across markets (Diebold and Yilmaz 2009). Furthermore, low-frequency data is more appropriate in assessing the likelihood and the driving moments of regime shifts across time (Wang and Theobald 2008).

The historical time series of exchange rate vis-à-vis the stock price over the study period are shown in Figure 1A. We can see from Figure 1A that most of the time for all countries, the series seem to be positively related, although for some periods the exchange rate and stock prices show a negative comovement.

The stock-market returns and changes in exchange rates are calculated by taking the natural $\log$ of the price ratios as follows:

$$
r_{t}=\ln \left(\frac{s_{t}}{s_{t-1}}\right) * 100
$$

and

$$
e_{t}=\ln \left(\frac{x_{t}}{x_{t-1}}\right) * 100
$$

where $s_{t}$ and $r_{t}$ are the stock price and stock market return at time $t . x_{t}$ and $e_{t}$ are the exchange rate and changes in exchange rate at time $t$. Figure $1 \mathrm{~B}$ shows the movement of weekly changes in the exchange rate and the stock price.

\subsection{Econometric Model}

We examined the relationship between exchange rates and stock prices of the selected countries. The baseline model used widely to describe the relationship between financial and economic time series is a VAR model specified as follows:

$$
y_{t}=\mu+\sum_{i=1}^{k} \gamma_{i} y_{t-i}+\varepsilon_{t}
$$

where $y_{t}$ represents exchange-rate changes and stock returns. If the two series are cointegrated, the VECM model is applied. The VECM is written as follows:

$$
y_{t}=\mu+\sum_{i=1}^{k} \gamma_{i} y_{t-i}+\alpha \dot{\beta} y_{t-1}+\varepsilon_{t}
$$

Equations (1) and (2) assume a linear relationship between the variables and cannot capture sudden changes in the data series. In Equation (2), $\alpha$ depicts the speed of adjustment and $\beta$ represents the cointegrating vectors. However, there is significant evidence that structural changes in the data series may have an impact on the relationship between the two variables. To account for structural changes, the Markov-switching model proposed by Krolzig (2001) was adopted to fulfil our objective. 
(A) Time series of the data

Cote d'Ivoire

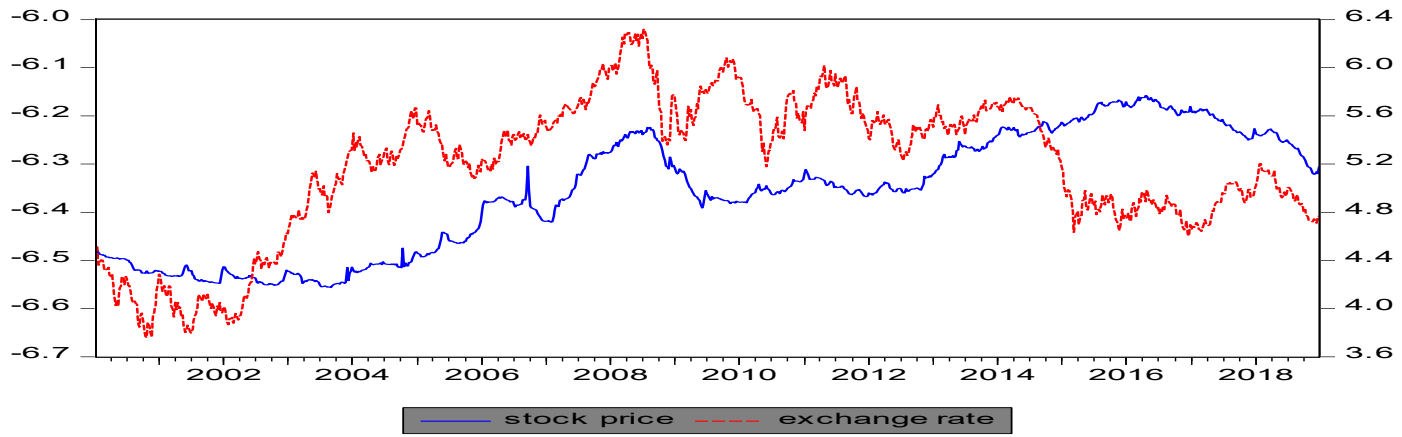

Ghana

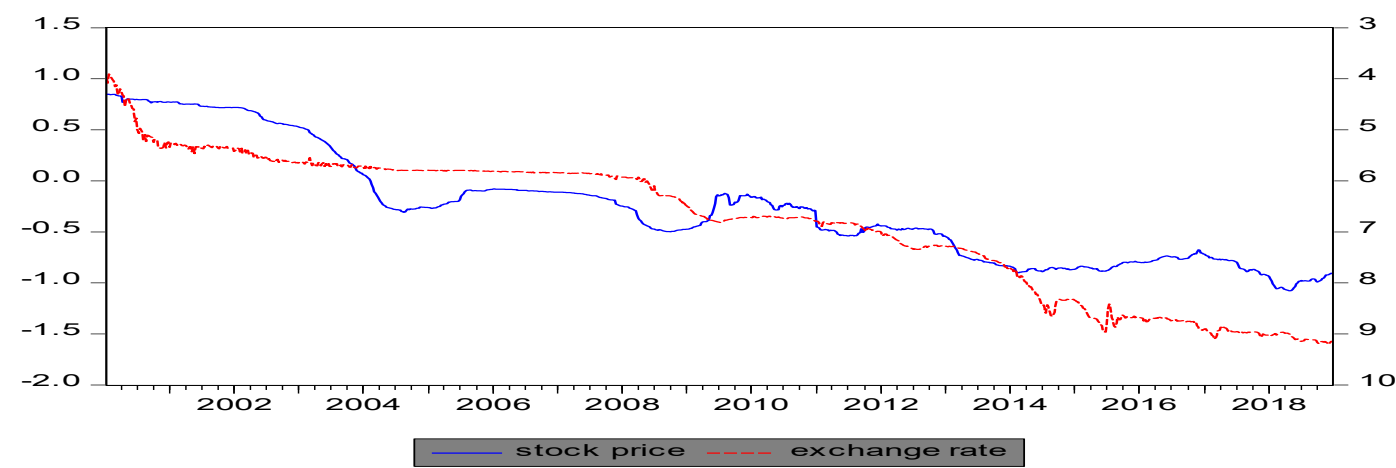

Kenya

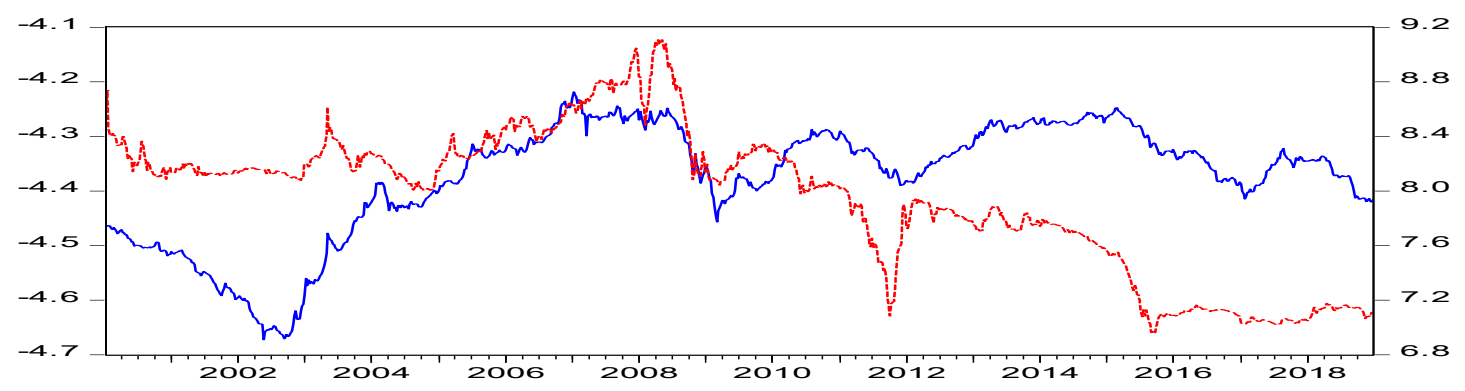

Mauritius

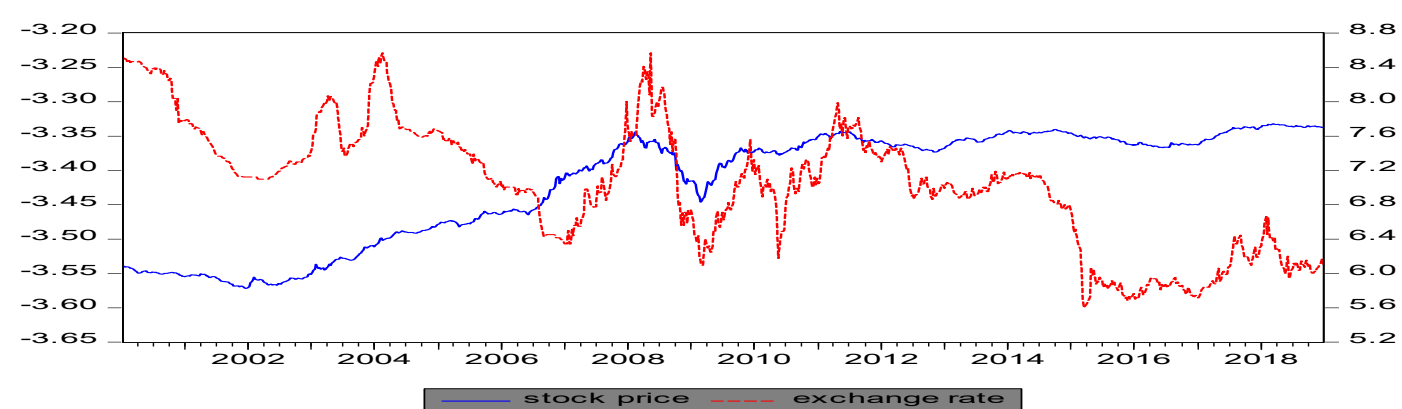

Nigeria

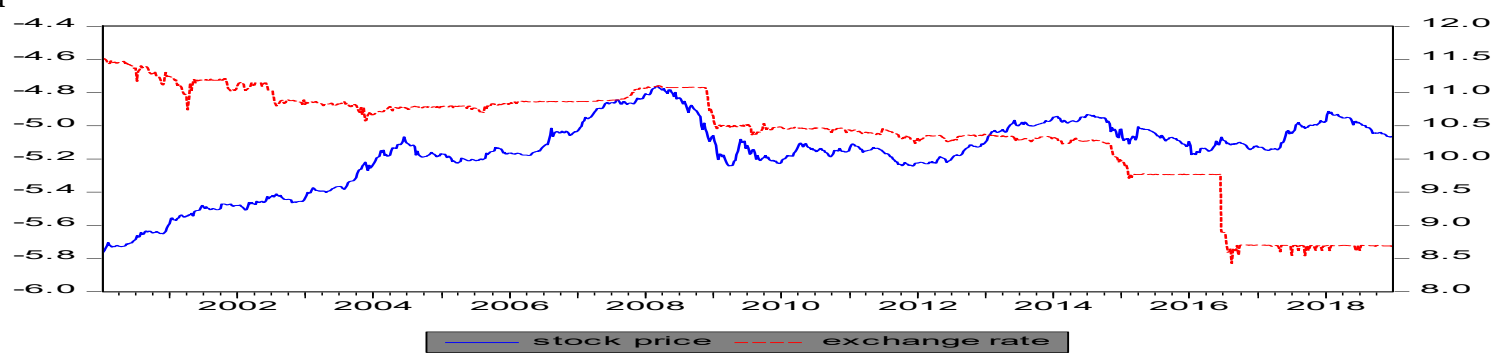

Figure 1. Cont. 
(B) Plot of stock-market returns and exchange-rate changes in separate graphs Stock-market returns

(a) Cote d'Ivoire

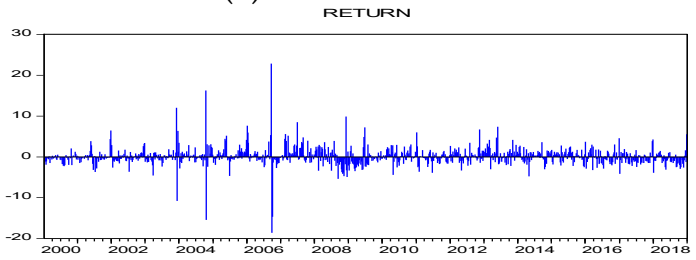

(b) Ghana

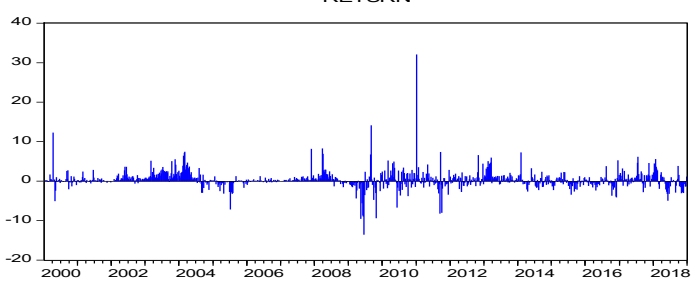

(c) Kenya

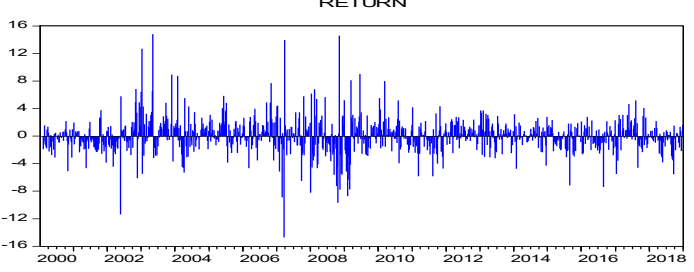

(d) Mauritius

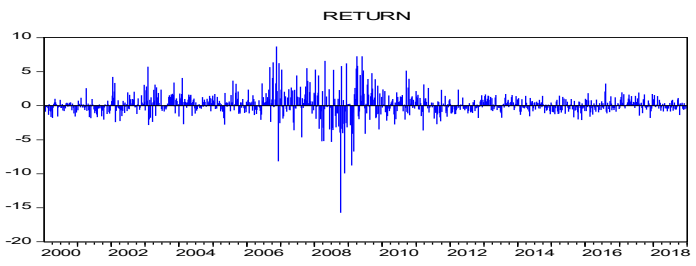

(e) Nigeria

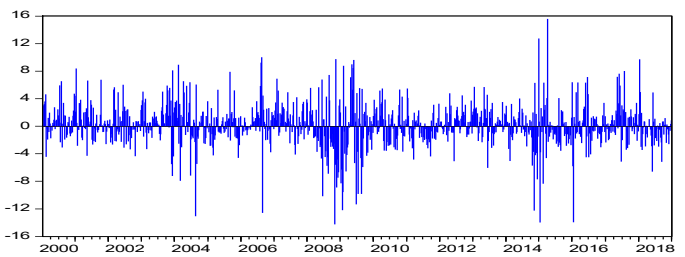

Changes in exchange rate

(f) Cote d'Ivoire

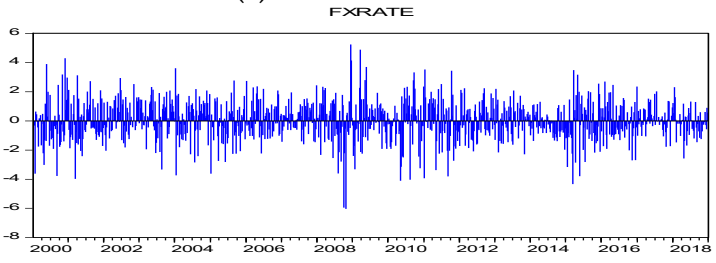

(g) Ghana

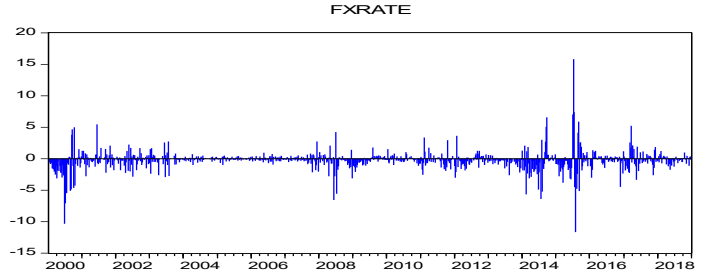

(h) Kenya

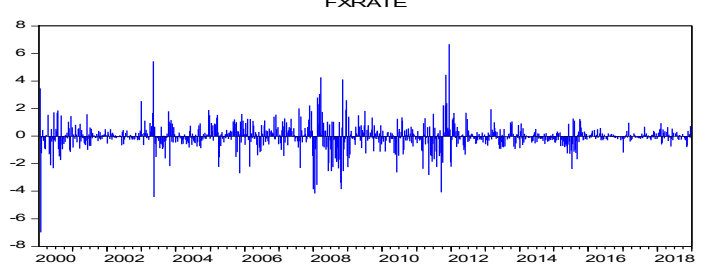

(i) Mauritius

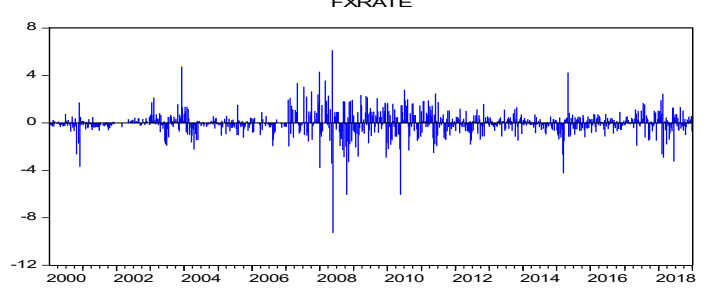

(j) $\underset{\text { FXRATE }}{\text { Nigeria }}$

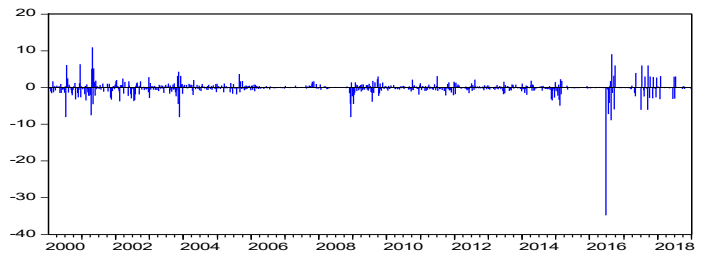

Figure 1. (A) Time series of the data. (B) Plot of stock-market returns and exchange-rate changes in separate graphs.

Following Krolzig (2001), this study modifies Hamilton's (1989) Markov-switching autoregressive model (MS-AR) of order $p$. The MS-AR $(p)$ model introduced by Hamilton (1989) assumes that the time-series variable $\left(y_{t}\right)$ is normally distributed with regime shifts in both mean $(\mu)$ and variance $\left(\delta^{2}\right)$. We assume $y_{t}$ switches between two states and is modelled by a Markov-switching autoregressive of order $p$, then the MS-AR $(p)$ model is given by:

$$
y_{t}=\mu\left(s_{t}\right)+\left[\sum_{i=1}^{k} \Phi_{j}\left(y_{t-i}-\mu\left(s_{t-i}\right)\right)\right]+\delta\left(s_{t}\right) \varepsilon_{t} \varepsilon_{t} \sim N I D\left(0, \delta^{2}\right)
$$

where $\left(y_{t}\right)$ represents exchange-rate changes or stock return, $\mu$ and $\delta$ depends on the regime $s_{t}$ at time $t$, phi $(\Phi)$ is autoregressive/model parameter and $\varepsilon_{t}$ is the white noise, and $s_{t}$ and $s_{t-i}$ are unobserved regimes variables that take the values 1 and 2 . For practical purposes, 
this study proposes a two-state model. This is sufficient to capture the dynamics of the data, representing a high- and a low-volatility regime.

Krolzig (2001) extends the MS-AR model and introduces MS-VAR/MS-VECM models. The MS-VAR model is an extension of Equation (3) presented above. This model is written as:

$$
\begin{gathered}
r_{t}=\omega_{s_{t}}+\sum_{j=1}^{k} \omega_{3 j}\left(s_{t}\right) r_{j-k}+\sum_{j=1}^{k} \omega_{4 j}\left(s_{t}\right) e_{j-k}+\gamma\left(s_{t}\right) \mu_{r, t} \mu_{r, t} \sim \operatorname{NID}(0,1) \\
e_{t}=\theta_{s_{t}}+\sum_{j=1}^{k} \theta_{3 j}\left(s_{t}\right) e_{j-k}+\sum_{j=1}^{k} \theta_{4 j}\left(s_{t}\right) r_{j-k}+\gamma\left(s_{t}\right) \mu_{e, t} \mu_{e, t} \sim \operatorname{NID}(0,1)
\end{gathered}
$$

whereas the MS-VECM model is written as:

$$
\begin{aligned}
& r_{t}=\omega_{s_{t}}+\sum_{j=1}^{k} \omega_{3 j}\left(s_{t}\right) r_{j-k}+\sum_{j=1}^{k} \omega_{4 j}\left(s_{t}\right) e_{j-k}+\alpha\left(s_{t}\right) \hat{\beta} r_{t-1}+\gamma\left(s_{t}\right) \mu_{r, t} \mu_{r, t} \sim \operatorname{NID}(0,1) \\
& e_{t}=\theta_{s_{t}}+\sum_{j=1}^{k} \theta_{3 j}\left(s_{t}\right) e_{j-k}+\sum_{j=1}^{k} \theta_{4 j}\left(s_{t}\right) r_{j-k}+\delta\left(s_{t}\right) \hat{\beta} e_{t-1}+\gamma\left(s_{t}\right) \mu_{e, t} \mu_{e, t} \sim \operatorname{NID}(0,1)
\end{aligned}
$$

where $r_{t}$ denotes the stock return and $e_{t}$ denotes changes in the exchange rate, $s_{t}$ is an unobserved regime variable, $\left(\mu_{t}\right)$ is an innovation process with a variance-covariance matrix $\gamma\left(s_{t}\right)$ depending on regime $\left(s_{t}\right)$. $\alpha\left(s_{t}\right)$ (or $\left.\delta\left(s_{t}\right)\right)$ represents the state-dependent adjustment coefficient. $\hat{\beta} r_{t-1}$ (or $\hat{\beta} e_{t-1}$ ) is the state-dependent cointegrating vector. Regime $s_{t}$ is defined by transition probabilities $p_{i j}$, which follows a first-order Markov process specified as:

$$
p_{i j}=P\left[s_{t}=j \mid s_{t-1}=i\right] \text { with } \sum_{j=1}^{2} P_{i j}=1, \text { for all } i, j \in\{1,2\}
$$

where

$$
\begin{gathered}
P_{11}=P\left[s_{t}=1 \mid s_{t-1}=1\right] \\
P_{12}=1-P_{11}=P\left[s_{t}=1 \mid s_{t-1}=2\right] \\
P_{22}=P\left[s_{t}=2 \mid s_{t-1}=2\right] \\
P_{21}=1-P_{22}=P\left[s_{t}=2 \mid s_{t-1}=1\right]
\end{gathered}
$$

Here, $s_{t}$ is assumed to follow a two-state Markov process and the Markov process is assumed to be ergodic and irreducible, where $p_{i j}$ denote the probability of being in regime $i$, given that the system was in regime $j$.

In addition, the transition probabilities provide us with an expected duration that is the length of time it takes for the system to stay in a particular regime. Thus, the expected duration is specified as:

$$
E(D)=\frac{1}{1-p_{i j}} \text {, where } i=1,2 \text { and } j=1,2 \ldots
$$

where $D$ denotes expected duration.

In Equations (4) and (6), the exchange rate is entered as exogenous variable that captures the effect of exchange-rate volatility on stock returns, while in Equations (5) and (7), the stock price is entered as an exogenous variable that captures the impact of stock returns on the exchange rate. Equations (4)-(7) are estimated by maximum likelihood, which is based on the expectation maximisation (EM) algorithm by Hamilton (1989). Further details of the estimation can be found in Krolzig (2001).

To estimate MS-VECM, we need to obtain the error-correction term; thus, we applied the Johansen cointegration test (Johansen and Juselius 1990). Although our study consists of bivariate models, we followed the empirical procedure of Migiakis and Bekiris (2009). 
This is represented in two forms, a trace statistics test and a maximum eigenvalue statistics test, specified as:

$$
\begin{gathered}
\operatorname{trace}(r, k)=-T \sum_{i=r+1}^{k} \ln \left(1-\hat{\lambda}_{i}\right) \\
\text { maximum eigen value }(r, r+1)=-T \ln \left(1-\hat{\lambda}_{r+1}\right)
\end{gathered}
$$

The Johansen trace statistic tests the null hypothesis that there are at most $r$ cointegrating relations $0 \leq r \leq k$ against the alternative $k$, where $k$ is the number of endogenous variables, while the maximum eigenvalue statistic tests the null hypothesis that there are $r$ cointegrating relations against the alternative hypothesis $r+1$ cointegrating relations. $T$ is the actual sample size, and $\hat{\lambda}_{i}$ is the $i$-th largest eigenvalue of the matrix. Further details of MS-VECM estimation can be found in Migiakis and Bekiris (2009).

\section{Results and Analysis}

\subsection{Descriptive Statistics}

Panels A and B in Table 2 provide descriptive statistics for stock returns and changes in exchange-rate series. The summary statistics in panel A report that the stock market in Ghana over the period had the highest mean return, while the Kenya stock market showed the lowest mean return. Concerning levels of volatility as indicated by the standard deviation, the stock market in Nigeria was the most volatile, followed by Kenya, Cote d'Ivoire, Ghana, and Mauritius. The results in Panel A further report a significantly skewed and higher kurtosis value for all return series. This shows an extreme deviation from normality, indicating that stock-return distribution was leptokurtic. Not surprisingly, the Jarque-Bera statistics test rejected the hypothesis of normal distribution, indicating that the stock returns were non-normal. In addition, the Ljung-Box statistics for testing autocorrelation in the squared returns series rejected the null hypothesis and showed evidence of serial correlation in all the return series except for Ghana. Visual evidence of the return series in Figure $1 \mathrm{~B}(\mathrm{a}-\mathrm{e})$ shows that the volatility of returns varied over time; hence, having lagged variables in the model regression is better.

\begin{tabular}{|c|c|c|c|c|c|c|}
\hline & Mean & Std. Dev. & Skewness & Kurtosis & J-B Test & LBQ \\
\hline \multicolumn{7}{|c|}{ Panel A: Stock returns } \\
\hline $\begin{array}{c}\text { Cote } \\
\text { d'Ivoire }\end{array}$ & 0.0693 & 2.1881 & 0.743 & 28.871 & $27672.26^{*}$ & $351.62 *$ \\
\hline Ghana & 0.3559 & 2.1767 & 3.155 & 54.217 & 109737.0 * & 7.81 \\
\hline Kenya & 0.0195 & 2.4649 & 0.363 & 9.683 & $1862.29 *$ & 209.25 * \\
\hline Mauritius & 0.1633 & 1.6767 & -0.650 & 16.233 & $7285.92 *$ & $675.91 *$ \\
\hline Nigeria & 0.1770 & 3.0692 & -0.273 & 6.814 & $611.78 *$ & 382.47 * \\
\hline \multicolumn{7}{|c|}{ Panel B: FX rate changes } \\
\hline $\begin{array}{c}\text { Cote } \\
\text { d'Ivoire }\end{array}$ & 0.0064 & 1.3541 & -0.179 & 4.195 & $64.18 *$ & $209.06^{*}$ \\
\hline Ghana & -0.2602 & 1.8521 & -0.137 & 16.583 & $7605.37 *$ & 641.73 * \\
\hline Kenya & -0.0378 & 0.9126 & -0.026 & 14.124 & $5099.55 *$ & 233.58 * \\
\hline Mauritius & -0.0304 & 0.9948 & -0.915 & 16.397 & $7533.69 *$ & 354.74 * \\
\hline Nigeria & -0.1147 & 1.7591 & -7.811 & 159.529 & 1019711.0 * & 11.838 \\
\hline
\end{tabular}

Table 2. Descriptive statistics.

Panels A and B show descriptive statistics for the stock-return and exchange-rate changes covering the period 14 January 2000-31 December 2018. StdDev—Standard deviation, J-B test-Jarque-Bera normality, LBQ_Ljung-Box Q-statistic test for autocorrelation applied to the squared returns of order $36 .{ }^{*}$ null hypothesis is rejected at $5 \%$ significance level.

Panel B in Table 2 shows that the means in exchange-rate changes for all sample markets were negative. This suggests a nominal appreciation against the US dollar, except for Cote d' Ivoire's CFA franc, which depreciated against the US dollar. Over the 
period, on average, Ghana enjoyed the highest appreciation to the US dollar and the most volatile, while the Kenyan shilling was the least volatile. Changes in exchange rates for all countries were negatively skewed and showed extreme deviation from normality. The Jarque-Bera test showed that the exchange-rate changes were different from a normal distribution. Figure $1 \mathrm{~B}(\mathrm{f}-\mathrm{j})$ displays visual evidence of exchange-rate returns. Interestingly, the descriptive statistics in Table 2 depict, on average, that the frontier markets selected were characterised by higher levels of return and volatility relative to the FX markets.

Table 3 presents unit root and stationarity tests for the data series. This study employs confirmatory data analysis by using three different tests; namely; the Augmented Dickey and Fuller test (Dickey and Fuller 1979), the Phillips and Perron test (Phillips and Perron 1988) and Kwiatkowski et al. test (Kwiatkowski et al. 1992). From the results in Table 3, the ADF and the PP tests showed evidence of unit root in the levels of all series. Similarly, the KPSS test rejected the null hypothesis of stationarity in levels of all series, suggesting that the series were nonstationary. However, after taking first differences, the ADF, PP, and KPSS tests suggested that the series was stationary. Thus, all three tests indicated that the stock-index and exchange-rate series were nonstationary in levels but stationary in first differences at a $5 \%$ significance level. This implies that the series were integrated of order 1 , i.e., I(1) and appropriate for further analysis.

Table 3. Unit root and stationary tests.

\begin{tabular}{ccccccc}
\hline & \multicolumn{2}{c}{ ADF -Test } & \multicolumn{2}{c}{ PP-Test } & \multicolumn{2}{c}{ KPSS-Test } \\
\cline { 2 - 7 } & Level & First Diff. & Level & First Diff. & Level & First Diff. \\
\hline Stock prices & & & & & \\
\hline Cote d'Ivoire & -1.0447 & $-30.2189^{* *}$ & -1.14202 & $-30.3903^{* *}$ & 3.1986 & $0.2101^{* *}$ \\
Ghana & -0.5161 & $-12.0554^{* *}$ & -0.5558 & $-25.8483^{* *}$ & 3.4856 & $0.2002^{* *}$ \\
Kenya & -1.3274 & $-27.6913^{* *}$ & -1.4793 & $-28.3337^{* *}$ & 1.5955 & $0.2150^{* *}$ \\
Mauritius & -0.7837 & $-27.1314^{* *}$ & -0.9026 & $-28.7238^{* *}$ & 3.6557 & $0.1862^{* *}$ \\
Nigeria & -2.1047 & $-29.0782^{* *}$ & -2.1215 & $-29.9269^{* *}$ & 1.3299 & $0.3693^{* *}$ \\
\hline Exchange rate & & & & & \\
\hline Cote d'Ivoire & -1.6459 & $-30.8514^{* *}$ & -1.6917 & $-30.8675^{* *}$ & 1.1040 & $0.1958^{* *}$ \\
Ghana & -1.8821 & $-35.6842^{* *}$ & -5.1669 & $-35.5633^{* *}$ & 3.8000 & $0.1789^{* *}$ \\
Kenya & -1.0624 & $-30.2303^{* *}$ & -1.2514 & $-30.6208^{* *}$ & 2.6528 & $0.0704^{* *}$ \\
Mauritius & -2.3552 & $-20.2765^{* *}$ & -2.4778 & $-33.0408^{* *}$ & 2.2963 & $0.0428^{* *}$ \\
Nigeria & -0.8008 & $-35.8716^{* *}$ & -0.8803 & $-35.5689^{* *}$ & 3.4035 & $0.1281^{* *}$ \\
\hline Null & & & & & \\
\hline
\end{tabular}

Null hypothesis for ADF and PP; $\mathrm{H}_{0}=$ series has unit root $\left(\mathrm{H}_{0}: \pi=0\right)$; null hypothesis for KPSS test; $\mathrm{H}_{0}=$ series is stationary. ${ }^{* *}$ indicates $5 \%$ significance level.

\subsection{Cointegration Test}

Having confirmed the order of integration, we further tested whether the variables were cointegrated. This was done using the Johansen cointegration test.

Table 4 presents the estimation results. We observed that the null hypothesis of no cointegration cannot be rejected at the $5 \%$ significance level as the trace statistics are less than the critical values. Similarly, the maximum eigenvalue test statistics are less than the critical values at the $5 \%$ significance level. Both techniques confirmed that the two variables were not cointegrated for all sample countries. This could be due to the presence of structural breaks in the relationship between the two variables, as argued by Phylaktis and Ravazzolo (2005). Moreover, failure to account for structural breaks may lead to inaccurate findings, as the linear cointegration regression may be biased (Tsagkanos and Siriopoulos 2013). As a consequence, the MS-VAR model used in this study is well specified, with no need to include error correction terms; hence we do not consider the MS-VECM/VECM model in further analyses. 
Table 4. Long-run cointegration test.

\begin{tabular}{|c|c|c|c|c|}
\hline & Trace & Statistics & Maximum & Eigenvalues \\
\hline$H_{0}$ & $\kappa_{\text {trace }}$ & 95\% Critical Value & $\kappa_{\max }$ & $95 \%$ Critical Value \\
\hline \multicolumn{5}{|c|}{ Cote d'Ivoire } \\
\hline$r=0$ & 9.665 & 15.495 & 6.755 & 14.265 \\
\hline$r \leq 1$ & 2.909 & 3.841 & 2.909 & 3.841 \\
\hline \multicolumn{5}{|l|}{ Ghana } \\
\hline$r=0$ & 5.851 & 15.495 & 4.086 & 14.265 \\
\hline$r \leq 1$ & 1.765 & 3.8418 & 1.765 & 3.841 \\
\hline \multicolumn{5}{|l|}{ Kenya } \\
\hline$r=0$ & 5.023 & 15.495 & 2.949 & 14.265 \\
\hline$r \leq 1$ & 2.074 & 3.841 & 2.074 & 3.841 \\
\hline \multicolumn{5}{|c|}{ Mauritius } \\
\hline$r=0$ & 11.082 & 15.495 & 9.115 & 14.265 \\
\hline$r \leq 1$ & 1.967 & 3.841 & 1.967 & 3.841 \\
\hline \multicolumn{5}{|c|}{ Nigeria } \\
\hline$r=0$ & 8.254 & 15.495 & 8.254 & 14.265 \\
\hline$r \leq 1$ & $6.07 \times 10^{-6}$ & 3.841 & $6.07 \times 10^{-6}$ & 3.841 \\
\hline
\end{tabular}

Note: $r$ denotes number of cointegrating vector under the null hypothesis. $H_{0}$ denotes null hypothesis. $H_{0}: r=0$ no cointegrating vectors; $H_{0}: r \leq 1$, one cointegrating vector. The $95 \%$ critical value is from MacKinnon et al. (1999).

\subsection{Transition from Cointegration Test}

We present further preliminary analysis concerning the possibility of nonlinearity in the relationship between the two variables. We do this by using the nonlinear dependency test known as the BDS test (Broock et al. 1996), which tests the null hypothesis of independently and identically distributed (IID) series against an unspecified alternative, including nonlinear dependence. The BDS test in Table 5 shows that the null hypothesis of IID was rejected for all sample countries, which signifies the existence of significant nonlinearities in the data series.

Table 5. BDS test.

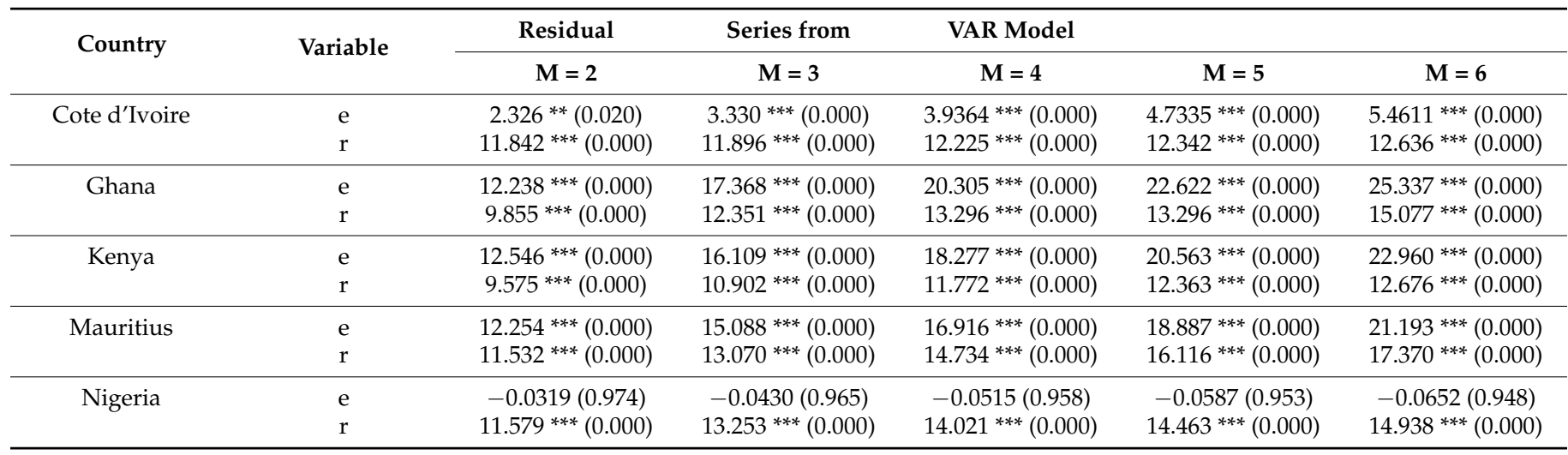

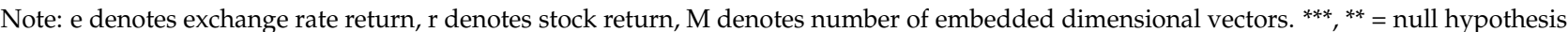
of whiteness is rejected at $1 \%$ and $5 \%$ significance levels, respectively.

Next, we applied the Bai and Perron (1998) multiple structural break test to check for unknown structural breaks in the series, since the two variables may have experienced different shocks over the sample period. Table 6 shows the results of the Bai-Perron test. The results suggested that there were at least four structural breaks in the data series for all countries. Again, using the MS model for further analysis was appropriate, since the model was able to detect structural breaks in the relationship between the variables. 
Table 6. Bai-Perron multiple-breakpoint tests.

\begin{tabular}{|c|c|c|c|c|c|c|c|c|c|c|c|}
\hline & 0 vs. 1 & 1 vs. 2 & 2 vs. 3 & 3 vs. 4 & 4 vs. 5 & $\begin{array}{l}\text { Number } \\
\text { of Breaks }\end{array}$ & BD1 & BD2 & BD3 & BD4 & BD5 \\
\hline Cote d'Ivoire & $4531.6^{* *}$ & $474.9^{* *}$ & $289.5^{* *}$ & $59.68 * *$ & $12.3^{* *}$ & 5 & 2003W10 & 2006W1 & 2009W9 & 2013W9 & 2016W10 \\
\hline Ghana & $2744.5^{* *}$ & $684.1^{* *}$ & $841.5^{* *}$ & $713.2 * *$ & 0.00 & 4 & $2002 W 47$ & 2008W31 & 2012W11 & 2015W3 & \\
\hline Kenya & $651.71 * *$ & $673.1^{* *}$ & $160.1^{* *}$ & $29.00 * *$ & 0.00 & 4 & 2005W4 & 2008W42 & 2012W35 & 2015W29 & \\
\hline Mauritius & $3108.5 * *$ & $750.2^{* *}$ & $74.2^{* *}$ & $191.3^{* *}$ & 0.00 & 4 & 2003W43 & $2006 W 46$ & 2010W38 & 2015W6 & \\
\hline Nigeria & $850.5^{* *}$ & $388.7^{* *}$ & $624.5^{* *}$ & $29.07 * *$ & 0.00 & 4 & 2006W10 & 2009W2 & $2012 W 50$ & 2016W3 & \\
\hline
\end{tabular}

Null hypothesis; $\mathrm{H}_{0}=\mathrm{L}+1$ vs. L sequentially determined structural breaks. ${ }^{* *}$ indicates significance at $5 \%$ level.

\subsection{Regime-Shifting Behaviour: Stock and FX Markets}

Before estimating the MS-AR $(p)$ model, the likelihood ratio (LR) test developed by Garcia and Perron (1996) enables us to choose the appropriate modelling technique. The LR test makes it possible to determine whether the stock returns and exchange rate changes exhibit regime-switching behaviour.

We tested the null of no switching in these markets represented by an AR model against an alternative MS-AR model that involves switching. The LR test results are displayed in Table 7 . The results showed that the $p$-values were highly significant, showing a strong rejection of the null hypothesis of no switching at a 5\% significance level. This implies that the stock and FX markets showed evidence of regime shifts and thus the nonlinear MS-AR model can be applied. This result is supported by past studies on emerging markets by Chkili and Nguyen (2014) and Kanas (2005), among others. Prior to estimating the LR test, we determined the lag length of the AR model. We employed the Akaike (AIC), Hannan and Quinn (HQIC), and Schwartz (SBIC) information criterion. The results showed that the AIC, HQIC, and SBIC suggested different models; however, the SBIC favoured the model with the lowest order. Therefore, the appropriate AR order selected by the SBIC was chosen. Box and Jenkins (1976) suggested that in choosing an appropriate model, it is fundamental to consider the principle of parsimony.

Table 7. LR test statistics.

\begin{tabular}{cccccc}
\hline & Cote D'Ivoire & Ghana & Kenya & Mauritius & Nigeria \\
\hline Panel a: stock & returns & & & & \\
\hline Linearity LR test & $589.19 *(0.00)$ & $794.30 *(0.00)$ & $335.45 *(0.00)$ & $618.64 *(0.00)$ & $314.14 *(0.00)$ \\
lnL(AR) & -2176.620 & -2113.510 & -2287.305 & -1903.423 & -2508.968 \\
lnL(MS-AR) & -1882.024 & -1716.360 & -2119.579 & -1602.629 & -2351.896 \\
\hline Panel b: FX rate & changes & & & & $1581.45 *(0.00)$ \\
\hline Linearity LR test & $78.82 *(0.00)$ & $983.01 *(0.00)$ & $725.87 *(0.00)$ & $618.64 *(0.00)$ & -1952.67 \\
lnL(AR) & -1702.49 & -2004.52 & -1308.39 & -1396.65 & -1161.95 \\
lnL(MS-AR) & -1663.08 & -1513.01 & -945.45 & -1087.33 & \\
\hline
\end{tabular}

Likelihood ratio test (LR) specified as: $\mathrm{LR}=2 \times\left|I n L_{M S}-A R-I n L_{A R}\right|{ }^{*}$ null hypothesis of no regime shift is rejected at a 5\% significance level. Figures in () brackets show Davies (1987) upper bound $p$-values.

We then estimated the MS-AR model (Equation (3)). The estimated results presented in Table 8 show the model estimation for stock returns (Panel A) and exchange-rate returns (Panel B).

\subsubsection{Stock Markets}

From Panel A in Table 8, the results showed that stock markets were characterised by two regimes, a low- and a high-volatility regime. These correspond to regime 1 and regime 2, respectively, and can be observed from the standard deviations, which were highly significant. They clearly specified two different regimes, with one regime being more volatile than the other. The most volatile stock market was Cote d'Ivoire, followed by Nigeria, Kenya, Ghana, and then Mauritius. Among all sample markets, Ghana and Mauritius had the lowest volatility in both the high- and low-volatility regimes. For all sample markets, the results showed a lower mean in regime 1 and a higher mean in regime 
2. This implies that the higher the level of volatility, the higher the return, contrary to the prediction that volatility should be higher when markets fall than when markets rise. Therefore, investors are compensated for the higher volatility in these markets (Ang and Bekaert 2002).

Table 8. MS-AR model estimation.

\begin{tabular}{|c|c|c|c|c|c|}
\hline & Cote D'Ivoire & Ghana & Kenya & Mauritius & Nigeria \\
\hline \multicolumn{6}{|l|}{$\begin{array}{l}\text { Panel A: Stock } \\
\text { return }\end{array}$} \\
\hline$\mu_{1}$ & $-0.050(0.054)$ & $0.204^{* * *}(0.040)$ & $0.0228(0.072)$ & $0.066(0.041)$ & $0.138(0.093)$ \\
\hline$\mu_{2}$ & $1.397 * *(0.695)$ & $0.593^{* * *}(0.236)$ & $0.008(0.399)$ & $0.464^{* *}(0.243)$ & $0.345(0.431)$ \\
\hline$\delta_{1}^{2}$ & $1.234^{* * *}(0.042)$ & $0.631^{* * *}(0.057)$ & $1.475^{* * *}(0.047)$ & $0.832 * * *(0.040)$ & $1.871^{* * *}(0.044)$ \\
\hline$\delta_{2}^{\frac{1}{2}}$ & $5.644^{* * *}(0.098)$ & $3.372 * * *(0.048)$ & $4.537^{* * *}(0.074)$ & $2.997^{* * *}(0.053)$ & $5.345^{* * *}(0.061)$ \\
\hline$\varnothing_{1}^{2}$ & $0.166^{* * *}(0.032)$ & $0.283^{* * *}(0.029)$ & $0.177^{* * *}(0.034)$ & $0.205^{* * *}(0.033)$ & $0.135^{* * *}(0.035)$ \\
\hline $\mathrm{P}_{11}$ & 0.957 & 0.904 & 0.949 & 0.981 & 0.963 \\
\hline $\mathrm{P}_{22}$ & 0.638 & 0.818 & 0.804 & 0.940 & 0.880 \\
\hline $\mathrm{D}_{1}$ & 23.00 & 10.41 & 19.59 & 52.66 & 27.23 \\
\hline $\mathrm{D}_{2}$ & 2.77 & 5.49 & 5.10 & 16.77 & 8.35 \\
\hline Log likelihood & -1881.045 & -1716.554 & -2119.579 & -1602.612 & -2351.832 \\
\hline $\mathrm{Q}^{2}(36)$ & $127.24^{\mathrm{a}}$ & 18.008 & $57.329^{a}$ & $153.66^{\mathrm{a}}$ & $55.496^{\mathrm{a}}$ \\
\hline \multicolumn{6}{|l|}{$\begin{array}{c}\text { Panel B: FX rate } \\
\text { changes }\end{array}$} \\
\hline$\mu_{1}$ & $0.055(0.046)$ & $-0.098^{* * *}(0.020)$ & $-0.036^{* *}(0.015)$ & $-0.032 * *(0.016)$ & $0.006(0.013)$ \\
\hline$\mu_{2}$ & $-0.101(0.115)$ & $-0.490^{* * *}(0.133)$ & $-0.038(0.069)$ & $-0.029(0.067)$ & $-0.333(0.205)$ \\
\hline$\delta_{1}^{2}$ & $1.089^{* *}(0.038)$ & $0.469^{* * *}(0.049)$ & $0.279^{* * *}(0.055)$ & $0.365^{* * *}(0.039)$ & $0.346^{* * *}(0.047)$ \\
\hline$\delta_{2}^{\frac{1}{2}}$ & $1.805^{* * *}(0.058)$ & $2.850^{* * *}(0.041)$ & $1.301^{* * *}(0.041)$ & $1.468^{* * *}(0.038)$ & $3.428^{* * *}(0.053)$ \\
\hline$\varnothing_{1}^{2}$ & $0.016(0.033)$ & $-0.105^{* * *}(0.032)$ & $-0.023(0.0353)$ & $-0.071^{* *}(0.032)$ & $-0.105^{* * *}(0.031)$ \\
\hline$\varnothing_{2}$ & - & - & $0.052 *(0.028)$ & - & - \\
\hline$\varnothing_{3}$ & - & - & $0.066^{* *}(0.032)$ & - & - \\
\hline $\mathrm{P}_{11}$ & 0.991 & 0.937 & 0.923 & 0.967 & 0.908 \\
\hline $\mathrm{P}_{22}$ & 0.980 & 0.905 & 0.896 & 0.954 & 0.719 \\
\hline $\mathrm{D}_{1}$ & 108.31 & 15.97 & 12.94 & 30.03 & 10.83 \\
\hline $\mathrm{D}_{2}$ & 50.74 & 10.50 & 9.66 & 21.85 & 3.56 \\
\hline Log likelihood & -1663.075 & -1513.014 & -945.450 & -1087.328 & -1161.945 \\
\hline $\mathrm{Q}^{2}(36)$ & 43.681 & $270.39^{a}$ & 18.206 & $65.271^{\mathrm{a}}$ & 1.627 \\
\hline
\end{tabular}

$\mathrm{Q}^{2}$ is the Ljung-Box Q-statistic test for autocorrelation applied to the squared residuals at lag $36 .{ }^{* * *}, * *$ and ${ }^{*}$ indicate coefficients were statistically significant at the $1 \%, 5 \%$ and $10 \%$ levels, respectively. Figures in () brackets are the standard errors. ${ }^{a}$ null hypothesis rejected at a $5 \%$ significance level.

Turning to average duration for the low-volatility regime, the results indicated the average duration was between 10 and 53 weeks; for the high-volatility regime, the results showed approximately 3 to 16 weeks. These findings were confirmed by the transition regimes; that is, the probability of being in regime 1 was greater than the probability of being in regime 2 , which is indicated by $P_{11}$ and $P_{22}$, respectively. When analysing the probability of staying in the low-volatility regime, the results ranged from 0.904 to 0.981 , while for the high-volatility regime, the probability was between 0.638 and 0.940 . This implies that the frontier markets were more likely to remain in the low-volatility regime for a longer period.

To further assist in the interpretation of the different regimes, Figure 2 displays the smoothed probability plot of being in the high-volatility regime. It can be seen from Figure $2 \mathrm{i}-\mathrm{v}$ that the smooth probability frequently switched from 0 and 1 , which can easily be classified as low- and high-volatility regimes respectively. For example, the high-volatility period common across sample markets appeared from mid-2008 to 2010. This period reflects the aftermath of the subprime financial crisis, which had an indirect effect on the frontier markets through a fall in commodity prices (Beck et al. 2011). For example, during this period, the stock-market value in Ghana and Nigeria fell by $46.6 \%$ 
and $60 \%$, respectively, due to loss of portfolio investment and risk premium volatility (Beck et al. 2011).

Stock return $(\mathbf{i}-\mathbf{v})$

(i) Cote D'Ivoire

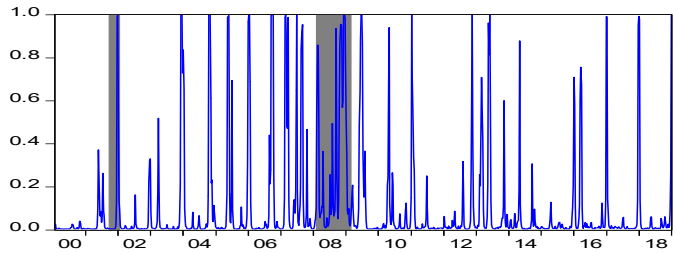

(ii) Ghana

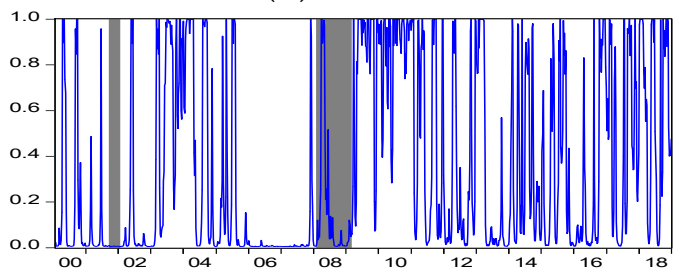

(iii) Kenya

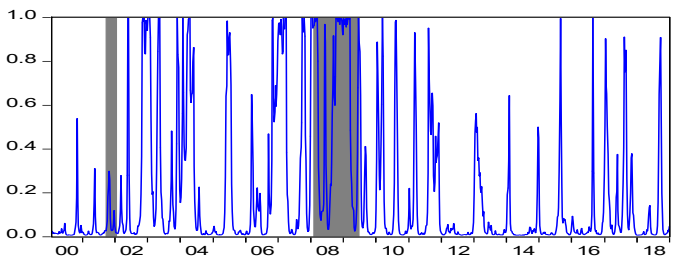

(iv) Mauritius

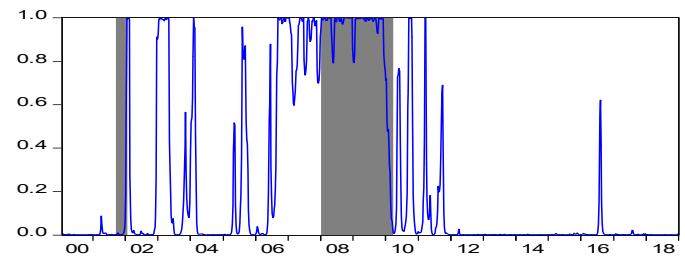

(v) Nigeria

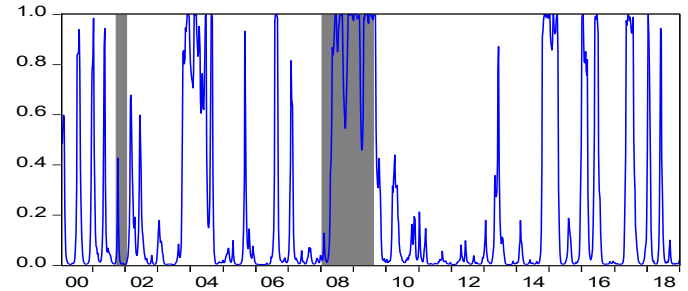

Changes in exchange rate (vi-x)

(vi) Cote D'Ivoire

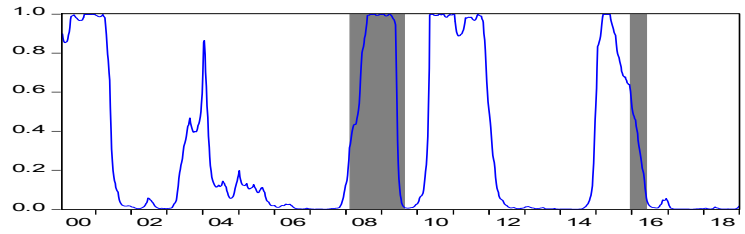

(vii) Ghana

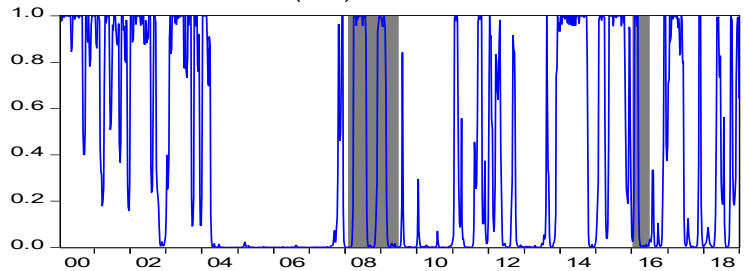

(viii) Kenya

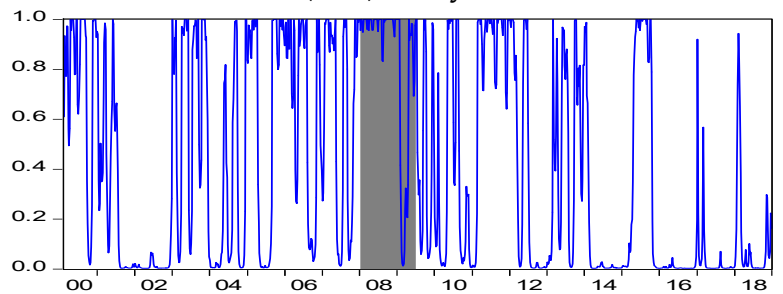

(ix) Mauritius

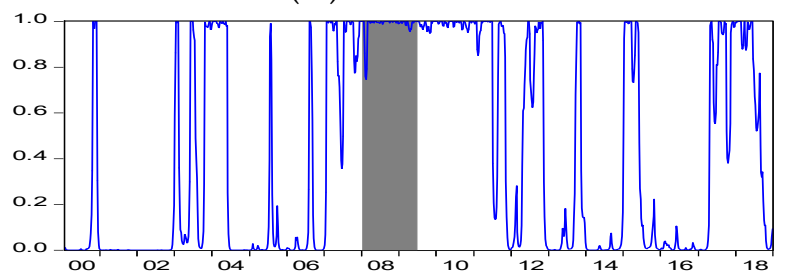

(x) Nigeria

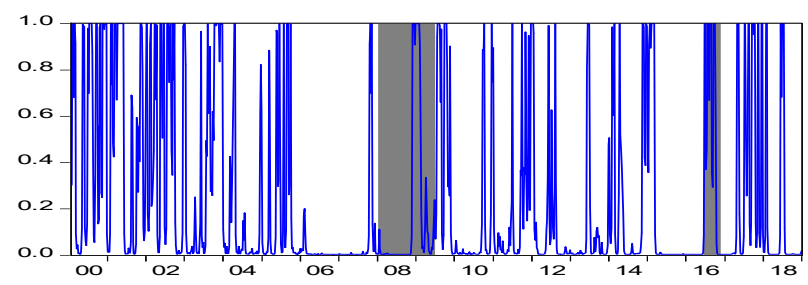

Figure 2. (i-v) show the probability of the stock returns being in regime 2. (vi-x) show the probability of exchange-rate changes being in regime 2 .

Further, we observed several high-volatility periods in the frontier markets, yet those periods did not coincide with global shocks such as "9/11" in 2001 and the European debt crisis in 2011. This may imply that the frontier markets in SSA were partially isolated from global shocks. This result may be attributed to the low correlation between frontier markets and developed markets. Moreover, these periods may reflect country-specific events such as political, social, and economic events. For example, in Kenya, Beck et al. (2011) argued that the fall in stock prices in Kenya during the financial crisis was due largely to domestic events such as broker fraud scandals and Safaricom's initial public offering in June 2008. The partial isolation from global shocks could be attributed to low foreign investor participation in Africa and low levels of integration (Ntim 2012). An 
exception is Mauritius; this may be due to its high levels of integration as observed by Sugimoto et al. (2014).

\subsubsection{FX Markets}

The results in Panel B of Table 8 show that the estimated variances were significant, which clearly indicated the presence of two regimes in the exchange-rate changes. The results showed that the variance in regime 2 was higher than regime 1 , which implies that regime 2 was more volatile than regime 1 . Hence, regime 1 and regime 2 were classified as low- and high-volatility regimes, respectively. Among the sample markets, the Kenyan exchange rate was the least volatile in both the low- and high-volatility regimes.

Furthermore, the probability of staying in regime $1\left(P_{11}\right)$ was higher than the probability of staying in regime $2\left(P_{22}\right)$ in all cases. The results showed that the probability of staying in the low- or high-volatility regime varied from 0.908 to 0.991 and 0.719 to 0.980 , respectively. The transition regime results were confirmed by the expected duration of staying in regime $1(\mathrm{~d} 1)$ and regime $2(\mathrm{~d} 2)$, which was between 10 and 108 weeks for regime 1 , and 4 and 51 weeks for regime 2 . This implies that regardless of the market, changes in the exchange-rate series persisted much longer in regime 1 than in regime 2, which suggests that the low-volatility regime was more persistent than the high-volatility regime for all countries.

It can be seen from Figure 2vi-x that the smooth probabilities plot of exchange-rate changes for all countries frequently moved in and out of the high-volatility regime. More significantly, Figure 2vi-x clearly shows a continuous rise in probability of occurrence of the high-volatility regime in 2001 and 2007 for all sample markets. These dates coincide with the " $9 / 11$ " US attacks and the global financial crisis, respectively. This implies that the exchange rate for all sample countries was significantly impacted by global shocks. This finding supports the World Bank's (2010) report that although the financial crisis originated in developed countries, it had an adverse impact on developing and emerging countries. In addition, the effect of the global financial crisis on Africa was mainly through currency fluctuation due to reduced capital flow, coupled with falling export receipts and remittances (Beck et al. 2011).

Further significant increase in volatility in the exchange-rate market for Cote d'Ivoire, Ghana, and Nigeria occurred in early 2016. This could be attributed to the collapse in oil prices, as these countries are classified as oil-producing countries.

Overall, the exchange rate in Cote d'Ivoire exhibited fewer high-volatility states compared to the others. This is not surprising, as the country employs a conventional peg exchange-rate regime (Countries that adopt a soft peg also maintain stability and strictly control exchange-rate volatility within a narrow margin of $2 \%$ (IMF 2016). According to IMF (2016), countries with pegged exchange rates tend to be associated with less volatility due to less direct exposure to cross-border capital flows.

Although the estimated smooth probability of being in regime 2 indicated common regime-switching patterns and several high volatility states, it seems difficult to link all the peaks to external events. Thus, they could be attributed to country-specific events.

\subsection{Dynamic Relationship between FX and Frontier Markets}

Having confirmed the regime-switching behaviour of each market, we are interested in determining if there is a regime-switching behaviour in the relationship between stock returns and exchange-rate changes. The MS-VAR model is used for this purpose, as identified previously.

\subsubsection{Model Selection}

In this section, we further justify the use of the nonlinear MS-VAR model over the linear VAR model; this is done using the LR test. The LR test makes it possible to choose the appropriate modelling technique, as stated earlier. Prior to estimating the LR test, we specified the lag length $(\mathrm{p})$ of the VAR model. This study employed three different 
criteria in specifying the VAR order: the AIC, the SBIC, and HQIC. The SBIC specified an optimal lag length for all markets. We then tested the null hypothesis of no switching in the relationship between the two variables represented by a linear VAR model against an alternative MS-VAR model, which involves switching using the LR test. The LR estimation results in Table 9 show that the $p$-values were highly significant for all markets, showing a strong rejection of the null hypothesis of no switching in the relationship between the variables at a 5\% significance level. This implies that the nonlinear MS-VAR model can be applied.

Table 9. LR test.

\begin{tabular}{cccc}
\hline & $\ln$ (MS-VAR) & $\operatorname{lnL}($ VAR $)$ & LR \\
\hline Cote D'Ivoire & -3575.269 & -3874.076 & $597.614^{*}(0.000)$ \\
Ghana & -3496.541 & -4112.774 & $1232.466^{*}(0.000)$ \\
Kenya & -3173.976 & -3568.460 & $788.968^{*}(0.000)$ \\
Mauritius & -2787.416 & -3285.943 & $997.055^{*}(0.000)$ \\
Nigeria & -3638.984 & -4451.712 & $1625.456^{*}(0.000)$ \\
\hline
\end{tabular}

The LR test is specified as $\mathrm{LR}=2^{*}\left|\operatorname{In} L_{M S}-V A R-\operatorname{In} L_{V A R}\right|{ }^{*}$ null hypothesis of no regime shift is rejected at a $5 \%$ significance level. Figures in () brackets show Davies upper bound $p$-values.

\subsubsection{MS-VAR Model Results}

The estimation results of the MS-VAR model (Equations (4) and (5)) are displayed in Table 10. From the results in Table 10, we can see that there were two distinct regimes in the relationship between stock prices and exchange rate. This can be identified from the standard deviation of both markets. The standard deviation in regime 1 was lower than in regime 2 for all countries. Thus, regime 1 can be described as a low-volatility regime, and regime 2 as a high-volatility regime. The table further reveals that the duration in the low-volatility regime for the countries was between 9 and 24 weeks, whereas the average duration in the high-volatility regime was between 3 and 12 weeks. This validates the transition regime, which is indicated by $P_{11}$ and $P_{22}$, respectively, suggesting that the low-volatility regime was more persistent than the high-volatility regime. Our findings are in line with Chkili and Nguyen (2014) and Kanas (2005).

The estimation results in Table 10 further show that the estimated coefficient capturing the impact of exchange-rate movements on the stock market $\left(\omega_{41}\right)$ in regime 1 was not significant in all cases expect for Mauritius, which had a positive effect. This suggests that changes in exchange rates had less direct impact on the frontier markets in the lowvolatility regime. Similar findings were reported for BRICS countries (Chkili and Nguyen 2014). Likewise, during the high-volatility regime $\left(\omega_{42}\right)$, the estimated coefficients were not significant for all countries except for Ghana and Kenya, which showed a significant positive effect of exchange-rate changes to stock returns. The results for Ghana and Kenya tally with the findings of Walid et al. (2011). The positive results for Ghana, Kenya, and Mauritius support the empirical prediction of the flow-oriented model, which suggests that depreciation of domestic currency will have a positive (negative) effect on export (import) firms, and thereby increase (reduce) their stock prices. These countries are relatively more import-dominant, therefore currency depreciation will increase their import costs, which in turn will lead to a negative impact on their stock markets. Moreover, these countries normally face trade deficits; therefore, depreciation of their currency is not favourable. 
Table 10. MS-VAR model estimation.

\begin{tabular}{|c|c|c|c|c|c|}
\hline & Cote D'Ivoire & Ghana & Kenya & Mauritius & Nigeria \\
\hline$\omega_{1}$ & $-0.026(0.046)$ & $0.150^{* * *}(0.043)$ & $0.053(0.067)$ & $0.038(0.034)$ & $0.260^{* * *}(0.087)$ \\
\hline$\omega_{2}$ & $0.182(0.679)$ & $0.110(0.226)$ & $-0.146(0.216)$ & $0.056(0.156)$ & $-0.050(0.347)$ \\
\hline$\omega_{31}$ & $0.187^{* * *}(0.029)$ & $0.331 * * *(0.026)$ & $0.249^{* * *}(0.031)$ & $0.256^{* * *}(0.037)$ & $0.119^{* * *}(0.027)$ \\
\hline$\omega_{32}$ & $-0.130 * *(0.065)$ & $0.333^{* * *}(0.030)$ & $-0.013(0.042)$ & $0.052(0.050)$ & $-0.030(0.061)$ \\
\hline$\omega_{41}$ & $0.011(0.035)$ & $0.070(0.044)$ & $-0.075(0.164)$ & $0.299 * * *(0.070)$ & $0.101(0.129)$ \\
\hline$\omega_{42}$ & $0.036(0.541)$ & $0.196^{* *}(0.098)$ & $0.341 * *(0.158)$ & $-0.035(0.108)$ & $0.145(0.194)$ \\
\hline$\theta_{1}$ & $-0.042(0.045)$ & $-0.149^{* * *}(0.030)$ & $-0.026(0.016)$ & $-0.072 * * *(0.019)$ & $-0.009(0.015)$ \\
\hline$\theta_{2}$ & $-0.004(0.229)$ & $-0.339 *(0.185)$ & $-0.171^{* *}(0.084)$ & $0.130(0.091)$ & $0.405(0.329)$ \\
\hline$\theta_{31}$ & $0.011(0.036)$ & $0.001(0.024)$ & $0.002(0.010)$ & $0.027(0.022)$ & $-0.007(0.007)$ \\
\hline$\theta_{32}$ & $0.040(0.043)$ & $0.021(0.121)$ & $-0.003(0.027)$ & $0.065(0.035)$ & $-0.030(0.080)$ \\
\hline$\theta_{41}$ & $0.039(0.034)$ & $-0.108^{* * *}(0.023)$ & $-0.052 *(0.028)$ & $-0.073^{* *}(0.031)$ & $-0.121^{* * *}(0.017)$ \\
\hline$\theta_{42}$ & $-0.019(0.110)$ & $-0.108^{* * *}(0.048)$ & $0.003(0.051)$ & $0.075 *(0.045)$ & $-0.221^{* * *}(0.042)$ \\
\hline Std.deviation & Stock returns & & & & \\
\hline$\delta_{1}^{2}$ & $1.252^{* * *}(0.000)$ & $0.976^{* * *}(0.000)$ & $1.611^{* * *}(0.000)$ & $0.804^{* * *}(0.000)$ & $2.208^{* * *}(0.000)$ \\
\hline$\delta_{2}^{2}$ & $5.616^{* * *}(0.000)$ & $3.354^{* * *}(0.000)$ & $3.512 * * *(0.000)$ & $2.625^{* * *}(0.000)$ & $4.711^{* * *}(0.000)$ \\
\hline Std.deviation & FX changes & & & & \\
\hline$\delta_{1}^{2}$ & $1.287^{* * *}(0.000)$ & $0.665^{* * *}(0.000)$ & $0.371^{* * *}(0.000)$ & $0.469^{* * *}(0.000)$ & $0.373^{* * *}(0.000)$ \\
\hline$\delta_{2}^{\frac{1}{2}}$ & $1.775^{* * *}(0.000)$ & $3.138^{* * *}(0.000)$ & $1.471^{* * *}(0.000)$ & $1.564^{* * *}(0.000)$ & $3.558 * * *(0.000)$ \\
\hline \multicolumn{6}{|l|}{ Probability } \\
\hline $\mathrm{P}_{11}$ & 0.96 & 0.90 & 0.92 & 0.95 & 0.90 \\
\hline $\mathrm{P}_{22}$ & 0.67 & 0.79 & 0.83 & 0.91 & 0.72 \\
\hline \multicolumn{6}{|l|}{ Av. duration } \\
\hline $\mathrm{D}_{1}$ & 24.64 & 10.42 & 12.37 & 20.11 & 9.74 \\
\hline $\mathrm{D}_{2}$ & 3.04 & 4.87 & 5.95 & 11.36 & 3.53 \\
\hline Correlation & coefficient & & & & \\
\hline Regime1 & 0.002 & 0.028 & 0.002 & 0.018 & -0.058 \\
\hline Regime2 & 0.063 & -0.002 & 0.163 & -0.016 & -0.002 \\
\hline
\end{tabular}

${ }^{* * *}, * *$, and ${ }^{*}$ indicate coefficients were statistically significant at the $1 \%, 5 \%$, and $10 \%$ levels, respectively. Figures in () brackets are the standard errors.

Irrespective of the regime, there was an insignificant impact of the exchange rates on stock returns for Nigeria and Cote d'Ivoire. This result is in line with Tule et al. (2018) for Nigeria. The fact that changes in the FX market did not affect the stock markets in Nigeria and Cote d'Ivoire could be as a result of effective hedging strategies against currency risks in Nigeria and exchange-rate arrangements in Cote d'Ivoire. Moreover, both countries fall under a strict exchange-rate arrangement known as the soft peg.

The effect of stock returns on exchange rates captured by $\left(\theta_{41}, \theta_{42}\right)$ was negative. This finding is consistent with theory and supports the stock-oriented model. The reverse relationship between the stock and FX markets suggests that an increase in stock-market returns led to depreciation of the exchange rate. This suggests that when the stock market is vibrant, it will attract foreign investors, which may lead to appreciation of the local currency. This finding is consistent with Chkili and Nguyen (2014). However, we noted some variations in Kenya, Mauritius, and Cote d'Ivoire. In Kenya and Mauritius, the negative effect was found only during the low-volatility period. In Cote d'Ivoire, we observed no significant effect in both the low- and high-volatility periods, which may be attributed to the strict controls on exchange rates. Similarly, this could be attributed to the small number of foreign investors, such that capital flow from foreign investors has no impact on the exchange rate. 
In addition, we can identify the correlation coefficients between stock and exchangerate returns in both low- and high-volatility regimes shown in Table 10. We noted that for Cote d' Ivoire and Kenya, the correlations increased significantly in regime 2, more than twice than that in regime 1. This could be described as a "contagion effect" (Forbes and Rigobon 2002). Similar results were found by Chkili and Nguyen (2014) for BRICS. However, for Ghana, Mauritius, and Nigeria, the correlation between the stock and exchangerate markets was lower during the high-volatility regime.

\subsubsection{Summary}

Our findings support the theoretical foundation on the comovement between stock prices and exchange rates. The impact of stock prices on exchange rates is negative, which is in accordance with the stock-oriented model, whereas the reverse effect is positive, which is consistent with the flow-oriented model. However, the stock-oriented model is more prevalent than the flow-oriented model in SSA. Besides, the flow-oriented effect was observed only in Ghana, Kenya (during crisis) and Mauritius (during noncrisis). Crisis periods refer to turbulent or high-volatility periods that could occur due to political instability, war, or economic or financial crises. Noncrisis periods refer to normal or lowvolatility periods. Moreover, these effects showed nonlinear and asymmetric characteristics, which implies that the MS model is a good fit for examining the relationship between the variables in these countries. For example, in Kenya, the effect of the exchange rate on stock prices in the high-volatility regime was positive (0.341) and significant, whereas in the low-volatility regime, the effect was negative $(-0.075)$ but not significant. Meanwhile, in Cote D'Ivoire, there was no significant effect in either direction. However, this is not surprising, since theoretical frameworks apply various restrictions and assumptions such that the "exchange rate is assumed to be free floating" (Lv et al. 2018).

\subsection{Robustness Checks}

\subsubsection{Alternative Time Periods}

When evaluating the sensitivity of our results in Section 4.5, we conducted robustness checks using alternative time periods to determine if the choice of MS-VAR or VAR as suggested by the likelihood ratio test (LRT) may change if we used three different subsample periods. Chen and Zhao (2009) argued that empirical results based on standard return tend to be sensitive to the time period. The entire sample was divided into three periods of equal length: first (14 January 2000-5 May 2006), second (12 May 2006-31 August 2012) and third (7 September 2012-28 December 2018) subsamples. These dates were also motivated through the endogenous breakpoint determination of the methodology proposed by Bai and Perron (1998); the optimal breakpoints identified were 2006 and 2012 (in 3 out of 5 cases). This section also used quantile regression analysis to check the robustness of our findings on the comovement between the variables on the full sample, pre- and post-crisis periods. It is believed that the relationship between stock prices and exchange rates might have been different before and after the crisis (Tsai 2015). Particularly, the global financial crisis is used as a cut-off point. Thus, we divided the study period into two subsamples as pre-crisis (14 February 2000-August 2008) and post-crisis (September 2008-December 2018). These subsample periods are consistent with Berger and Uddin (2016).

The LRT results in Table 11 show statistically significant $p$-values, indicating that the VAR was rejected for the three subsamples. This implies that the MS-VAR model is appropriate for the period examined. 
Table 11. Subsample LR test.

\begin{tabular}{cccc}
\hline & lnL(MSVAR) & lnL(VAR) & LR \\
\hline First subsample & & & \\
Cote D'Ivoire & -1117.274 & -1279.180 & $323.812^{*}(0.00)$ \\
Ghana & -1127.399 & -1297.658 & $340.518^{*}(0.00)$ \\
Kenya & -1059.875 & -1171.700 & $223.65^{*}(0.00)$ \\
Mauritius & -655.629 & -812.882 & $314.506^{*}(0.00)$ \\
Nigeria & -1252.044 & -1388.922 & $273.756^{*}(0.00)$ \\
\hline Second subsample & & & \\
Cote D'Ivoire & -1286.433 & -1394.955 & $217.044^{*}(0.00)$ \\
Ghana & -1014.642 & -1254.163 & $479.042^{*}(0.00)$ \\
Kenya & -1250.690 & -1352.469 & $203.558^{*}(0.00)$ \\
Mauritius & -1267.273 & -1348.796 & $163.046^{*}(0.00)$ \\
Nigeria & -1130.676 & -1305.399 & $349.446^{*}(0.00)$ \\
\hline Third subsample & & & \\
Cote D'Ivoire & -1106.306 & -1134.672 & $56.732 *(0.00)$ \\
Ghana & -1137.467 & -1272.684 & $270.434^{*}(0.00)$ \\
Kenya & -770.0504 & -839.1036 & $138.106 *(0.00)$ \\
Mauritius & -705.760 & -763.749 & $115.978^{*}(0.00)$ \\
Nigeria & -1110.044 & -1584.507 & $948.926^{*}(0.00)$ \\
\hline
\end{tabular}

${ }^{*}$ null hypothesis of no regime shift is rejected at a $5 \%$ significance level. Figures in () brackets show Davies upper bound $p$-values. The first, second, and third subsamples correspond to 14 January 2000-5 May 2006, 12 May 2006-31 August 2012, and 7 September 2012-28 December 2018, respectively.

\subsubsection{Quantile Regression}

An important result given in Section 4.5 was that the stock market had a significant impact on the FX market, rather than the reverse effect, and the comovement between the two variables was subject to regime changes. To check for robustness, we investigated the comovement between the two variables using the quantile regression $(\mathrm{QR})$ model. We present results for the full sample, pre-crisis, and post-crisis periods. The QR model allows the effect of the independent variables to vary across several quantiles; thus, we inferred whether the comovement between the variables was subject to different market conditions. The benchmark model of the QR is the standard OLS; hence, we applied that to facilitate further comparison of our results.

The QR model was employed to investigate the effect of exchange rates on stock return and vice versa.

Comparing the results from the MS-VAR model and the quantile regression, a significant effect from stock prices to exchange rates was observed, and an insignificant reverse effect was observed, which is consistent for the full sample, pre-crisis, and post-crisis periods. This confirms our previously obtained results that the stock-oriented model played a significant role, rather than the reverse effect. Similarly, the results indicated that the relationship between the two variables was changed by the crisis. Moreover, the exchange rate reacted differently to stock returns when the stock market was bearish, rather than when bullish. The QR model also showed that the effect of exchange rates on stock returns and the reverse effect varied in sign, magnitude, and significance. This further confirmed our results that the relationship between the variables was subject to regime changes.

The patterns can be seen clearly in Table 12a,b (full sample), Table 13a,b (pre-crisis) and Table 14a,b (post-crisis). For instance, in Table 12a, the OLS model confirmed the positive effect of exchange-rate changes on stock returns. However, all countries were statistically insignificant except for Kenya. Likewise, the QR model showed an insignificant effect of exchange rates on stock returns for all countries except for Kenya and Nigeria (when the market is bearish). Both OLS and QR confirmed our earlier results that movement in exchange rates had less significant impact on frontier markets in SSA. 
Table 12. Effects of (a) exchange rates on stock prices and (b) stock prices on exchange rates.

\begin{tabular}{|c|c|c|c|c|c|c|c|c|c|c|c|}
\hline \multicolumn{12}{|c|}{ (a) Exchange Rates on Stock Prices } \\
\hline \multirow[t]{2}{*}{ Country } & Variable & OLS & Bearish & Market & & Normal & Market & & Bullish & Market & \\
\hline & & & $Q_{0.1}$ & $\mathbf{Q}_{0.2}$ & $\mathbf{Q}_{0.3}$ & $\mathbf{Q}_{0.4}$ & $\mathrm{Q}_{0.5}$ & $\mathbf{Q}_{0.6}$ & $\mathbf{Q}_{0.7}$ & $\mathbf{Q}_{0.8}$ & $\mathbf{Q}_{0.9}$ \\
\hline \multirow[t]{2}{*}{ Cote d'Ivoire } & $\beta_{0}$ & 0.069 & $-1.807^{* * *}$ & $-1.115^{* * *}$ & $-0.663^{* * *}$ & $-0.308 * * *$ & -0.039 & $0.250 * * *$ & $0.555^{* * *}$ & $1.098^{* * *}$ & $2.131^{* * *}$ \\
\hline & $B_{1}$ & 0.022 & 0.016 & 0.034 & 0.002 & 0.014 & 0.004 & 0.025 & 0.017 & -0.004 & -0.094 \\
\hline \multirow{2}{*}{ Ghana } & $\beta_{0}$ & 0.357 & $-1.339^{* * *}$ & $-0.510^{* * *}$ & $-0.149^{* * *}$ & 0.032 & $0.185^{* * *}$ & $0.404^{* * *}$ & $0.731^{* * *}$ & $1.210^{* * *}$ & $2.240^{* * *}$ \\
\hline & $\beta_{1}$ & 0.004 & -0.001 & 0.021 & 0.001 & 0.003 & 0.002 & 0.001 & 0.011 & 0.025 & 0.011 \\
\hline \multirow[t]{2}{*}{ Kenya } & $\beta_{0}$ & 0.038 & $-2.493^{* * *}$ & $-1.560 * * *$ & $-0.821 * * *$ & $-0.368 * * *$ & 0.000 & $0.400 * * *$ & $0.917^{* * *}$ & $1.535^{* * *}$ & $2.451^{* * *}$ \\
\hline & $B_{1}$ & $0.510 * * *$ & $0.260 *$ & $0.367^{* * *}$ & $0.335^{* * *}$ & 0.268 ** & $0.252 * *$ & $0.334 * *$ & $0.270 *$ & $0.415^{* * *}$ & $0.407^{* * *}$ \\
\hline \multirow[t]{2}{*}{ Mauritius } & $\beta_{0}$ & $0.164^{* * *}$ & -1.246 & -0.733 & -0.375 & -0.177 & 0.098 & 0.341 & 0.590 & 1.025 & 1.696 \\
\hline & $B_{1}$ & 0.045 & -0.065 & 0.035 & 0.007 & 0.008 & 0.036 & 0.070 & 0.074 & 0.057 & 0.047 \\
\hline \multirow[t]{2}{*}{ Nigeria } & $\beta_{0}$ & $0.175 *$ & $-2.858^{* * *}$ & $-1.747^{* * *}$ & $-0.962 * * *$ & $-0.389 * * *$ & $0.190 * *$ & $0.642 * * *$ & $1.224^{* * *}$ & $2.053^{* * *}$ & $3.510^{* * *}$ \\
\hline & $B_{1}$ & -0.012 & $0.225 * * *$ & $0.123 *$ & 0.135 & 0.000 & -0.063 & $-0.116^{* * *}$ & $-0.099^{* * *}$ & -0.099 & -0.192 \\
\hline \multicolumn{12}{|c|}{ (b) Stock Prices on Exchange Rates } \\
\hline \multirow[t]{2}{*}{ Country } & Variable & OLS & Bearish & Market & & Normal & Market & & Bullish & Market & \\
\hline & & & $\mathrm{Q}_{0.1}$ & $\mathrm{Q}_{0.2}$ & $\mathbf{Q}_{0.3}$ & $\mathrm{Q}_{0.4}$ & $\mathrm{Q}_{0.5}$ & $\mathbf{Q}_{0.6}$ & $\mathrm{Q}_{0.7}$ & $\mathrm{Q}_{0.8}$ & $\mathbf{Q}_{0.9}$ \\
\hline \multirow[t]{2}{*}{ Cote d'Ivoire } & $B_{0}$ & 0.005 & $-1.602 * * *$ & $-1.007^{* * *}$ & $-0.621^{* * *}$ & $-0.293^{* * *}$ & -0.009 & $0.311^{* * *}$ & $0.675^{* * *}$ & $1.114^{* * *}$ & $1.660^{* * *}$ \\
\hline & $B_{1}$ & 0.008 & 0.030 & 0.029 & 0.024 & $0.035^{* *}$ & $0.032 * *$ & 0.011 & -0.009 & -0.017 & -0.016 \\
\hline \multirow[t]{2}{*}{ Ghana } & $\beta_{0}$ & $-0.261^{* * *}$ & $-1.899^{* * *}$ & $-0.923^{* * *}$ & $-0.519^{* * *}$ & $-0.280^{* * *}$ & -0.126 & -0.016 & $0.094^{* * *}$ & $0.407^{* * *}$ & $1.123^{* * *}$ \\
\hline & $B_{1}$ & 0.003 & -0.054 & $-0.045^{* *}$ & -0.009 & 0.002 & 0.010 & 0.006 & 0.005 & 0.010 & 0.073 \\
\hline \multirow[t]{2}{*}{ Kenya } & $\beta_{0}$ & -0.039 & $-0.899 * * *$ & $-0.463^{* * *}$ & $-0.234^{* * *}$ & $-0.134^{* * *}$ & $-0.037^{* *}$ & $0.053^{* * *}$ & $0.177^{* * *}$ & $0.375^{* * *}$ & $0.835^{* * *}$ \\
\hline & $B_{1}$ & $0.070^{* * *}$ & $0.091 * * *$ & $0.049^{* * *}$ & $0.031 * * *$ & $0.020 * * *$ & $0.016^{* * *}$ & $0.014^{* *}$ & $0.015^{* *}$ & 0.024 & $0.061^{* * *}$ \\
\hline \multirow[t]{2}{*}{ Mauritius } & $\mathrm{B}_{0}$ & -0.033 & $-1.037^{* * *}$ & $-0.529^{* * *}$ & $-0.257^{* * *}$ & $-0.133^{* * *}$ & 0.000 & $0.038^{* *}$ & $0.231^{* * *}$ & $0.478^{* * *}$ & $0.949 * * *$ \\
\hline & $\beta_{1}$ & 0.016 & $0.048^{* *}$ & 0.036 & 0.011 & 0.011 & 0.000 & 0.004 & 0.017 & 0.010 & 0.010 \\
\hline \multirow[t]{2}{*}{ Nigeria } & $\beta_{0}$ & $-0.113^{* *}$ & $-1.080^{* * *}$ & $-0.426^{* * *}$ & $-0.189^{* * *}$ & $-0.055^{* * *}$ & -0.000 & $0.040^{* * *}$ & $0.128^{* * *}$ & $0.364^{* * *}$ & $0.801 * * *$ \\
\hline & $\beta_{1}$ & -0.004 & 0.006 & -0.003 & -0.003 & 0.000 & 0.000 & 0.001 & 0.004 & 0.008 & $0.037^{* * *}$ \\
\hline
\end{tabular}

(a): Bearish $(\tau=0.10,0.20,0.30)$, normal $(\tau=0.40,0.50,0.60)$, bullish $(\tau=0.70,0.80,0.90) . B_{0}$ denotes constant, $B_{1}$ denotes coefficient of exchange-rate changes. ${ }^{* * *}, * *$, and $*$ indicate statistical significance at $1 \%, 5 \%$, and $10 \%$ levels, respectively. (b): Bearish $(\tau=0.10,0.20,0.30)$, normal $(\tau=0.40,0.50,0.60)$, bullish $(\tau=0.70,0.80,0.90) . \beta_{0}$ denotes constant, $\beta_{1}$ denotes coefficient of stock returns. ${ }^{* * *},{ }^{* *}$ indicate statistical significance at $1 \%, 5 \%$, and $10 \%$ levels respectively.

Table 13. Effects of (a) exchange rates on stock prices (pre-crisis) and (b) exchange rates on stock prices (post-crisis).

\begin{tabular}{|c|c|c|c|c|c|c|c|c|c|c|c|}
\hline \multicolumn{12}{|c|}{ (a) Exchange Rates on Stock Prices (Pre-Crisis) } \\
\hline \multirow[t]{2}{*}{ Country } & Variable & OLS & Bearish & Market & & Normal & Market & & Bullish & Market & \\
\hline & & & $Q_{0.1}$ & $\mathrm{Q}_{0.2}$ & $\mathbf{Q}_{0.3}$ & $Q_{0.4}$ & $\mathrm{Q}_{0.5}$ & $Q_{0.6}$ & $\mathrm{Q}_{0.7}$ & $\mathbf{Q}_{0.8}$ & $Q_{0.9}$ \\
\hline \multirow[t]{2}{*}{ Cote d'Ivoire } & $B_{0}$ & $0.215^{*}$ & $-1.382 * * *$ & $-0.773^{* * *}$ & $-0.484^{* * *}$ & $-0.212 * * *$ & -0.009 & $0.230 * * *$ & $0.533^{* * *}$ & $0.975^{* * *}$ & $2.378^{* * *}$ \\
\hline & $\beta_{1}$ & 0.069 & 0.062 & 0.040 & -0.012 & 0.016 & -0.007 & 0.050 & -0.034 & -0.087 & -0.069 \\
\hline \multirow{2}{*}{ Ghana } & $\beta_{0}$ & $0.588^{* * *}$ & $-0.348^{* * *}$ & -0.028 & 0.035 & $0.109^{* * *}$ & $0.232 * * *$ & $0.437^{* * *}$ & $0.746^{* * *}$ & $1.194^{* * *}$ & $2.271^{* * *}$ \\
\hline & $\beta_{1}$ & -0.029 & -0.026 & $-0.003^{* *}$ & -0.001 & -0.009 & -0.003 & 0.002 & 0.012 & -0.038 & -0.006 \\
\hline \multirow[t]{2}{*}{ Kenya } & $\beta_{0}$ & 0.153 & $-2.517^{* * *}$ & $-1.558^{* * *}$ & $-0.839^{* * *}$ & $-0.423^{* * *}$ & -0.055 & $0.476^{* * *}$ & $1.063^{* * *}$ & $1.791^{* * *}$ & $2.852 * * *$ \\
\hline & $\beta_{1}$ & $0.042^{* * *}$ & 0.196 & $0.366^{* *}$ & 0.215 & 0.206 & 0.153 & 0.224 & 0.190 & 0.408 & 0.611 * \\
\hline \multirow[t]{2}{*}{ Mauritius } & $\beta_{0}$ & $0.292 * * *$ & $-1.351^{* * *}$ & $-0.684^{* * *}$ & $-0.321^{* * *}$ & -0.090 & $0.198^{* * *}$ & $0.419^{* *}$ & $0.760^{* * *}$ & $1.195^{* * *}$ & $2.070^{* * *}$ \\
\hline & $\beta_{1}$ & -0.100 & $-0.135^{* * *}$ & -0.063 & -0.030 & -0.013 & -0.011 & -0.011 & -0.061 & -0.047 & -0.038 \\
\hline \multirow[t]{2}{*}{ Nigeria } & $\beta_{0}$ & $0.475^{* * *}$ & $-2.454^{* * *}$ & $-1.411^{* * *}$ & $-0.701^{* * *}$ & $-0.040^{* * *}$ & 0.380 & $0.807^{* * *}$ & $1.395^{* * *}$ & $2.280^{* * *}$ & $3.795^{* * *}$ \\
\hline & $B_{1}$ & $-0.230^{* *}$ & -0.177 & -0.153 & -0.058 & -0.094 & -0.171 & $-0.289 * *$ & $-0.268^{* *}$ & $-0.179 * * *$ & $-0.344^{* * *}$ \\
\hline \multicolumn{12}{|c|}{ (b) Exchange Rates on Stock Prices (Post-Crisis). } \\
\hline \multirow[t]{2}{*}{ Country } & Variable & OLS & Bearish & Market & & Normal & Market & & Bullish & Market & \\
\hline & & & $\mathrm{Q}_{0.1}$ & $\mathrm{Q}_{0.2}$ & $\mathbf{Q}_{0.3}$ & $\mathrm{Q}_{0.4}$ & $\mathbf{Q}_{0.5}$ & $\mathrm{Q}_{0.6}$ & $\mathbf{Q}_{0.7}$ & $\mathbf{Q}_{0.8}$ & $\mathbf{Q}_{0.9}$ \\
\hline \multirow[t]{2}{*}{ Cote d'Ivoire } & $B_{0}$ & -0.058 & $-2.076^{* * *}$ & $-1.424^{* * *}$ & $-0.917 * * *$ & $-0.400 * * *$ & -0.073 & $0.270 * * *$ & $0.651 * * *$ & $1.122^{* * *}$ & $1.859^{* * *}$ \\
\hline & $\beta_{1}$ & -0.022 & -0.068 & 0.003 & -0.011 & -0.023 & 0.017 & 0.006 & -0.023 & -0.023 & -0.140 \\
\hline \multirow[t]{2}{*}{ Ghana } & $\beta_{0}$ & -0.169 & $-1.755^{* * *}$ & $-0.947^{* * *}$ & $-0.520 * * *$ & $-0.198^{* * *}$ & -0.081 & $0.371^{* * *}$ & $0.716^{* * *}$ & $1.254^{* * *}$ & $2.189^{* * *}$ \\
\hline & $B_{1}$ & 0.054 & $0.866^{* *}$ & 0.044 & 0.026 & 0.005 & 0.026 & 0.045 & 0.029 & 0.081 & 0.017 \\
\hline \multirow[t]{2}{*}{ Kenya } & $\beta_{0}$ & -0.050 & $-2.511 * * *$ & $-1.531^{* * *}$ & $-0.733 * * *$ & $-0.334^{* * *}$ & 0.023 & $0.379 * * *$ & $0.837^{* * *}$ & $1.395 * * *$ & $2.196^{* * *}$ \\
\hline & $B_{1}$ & $0.603^{* * *}$ & $0.391 * * *$ & 0.421 ** & $0.424^{* * *}$ & $0.419^{* * *}$ & 0.357 * & 0.373 * & 0.411 * & 0.532 *** & 0.380 * \\
\hline \multirow[t]{2}{*}{ Mauritius } & $\beta_{0}$ & 0.059 & $-1.177^{* * *}$ & $-0.794^{* * *}$ & $-0.459^{* * *}$ & $-0.227^{* * *}$ & 0.014 & $0.277^{* *}$ & $0.513^{* * *}$ & $0.880^{* * *}$ & $1.467^{* * *}$ \\
\hline & $B_{1}$ & $0.159 * *$ & 0.003 & 0.093 & 0.132 * & 0.077 & 0.133 * & 0.126 * & $0.182^{* * *}$ & $0.199 * *$ & $0.125 * *$ \\
\hline \multirow[t]{2}{*}{ Nigeria } & $\mathrm{B}_{0}$ & -0.068 & $-3.200 * * *$ & $-2.010^{* * *}$ & $-1.128 * * *$ & $-0.663^{* * *}$ & 0.031 & $0.498^{* * *}$ & $1.042 * * *$ & $1.859 * * *$ & $3.229^{* * *}$ \\
\hline & $\beta_{1}$ & 0.064 & $0.584^{* *}$ & 0.386 * & 0.255 & 0.265 & 0.046 & $-0.089 *$ & -0.057 & $-0.081^{* * *}$ & $-0.041^{* *}$ \\
\hline
\end{tabular}

Bearish $(\tau=0.10,0.20,0.30)$, normal $(\tau=0.40,0.50,0.60)$, bullish $(\tau=0.70,0.80,0.90)$. $\beta_{0}$ denotes constant, $\beta_{1}$ denotes coefficient of exchange-rate changes. ${ }^{* * *}, * *$, and ${ }^{*}$ indicate statistical significance at $1 \%, 5 \%$, and $10 \%$ levels, respectively. 
Table 14. Effects of (a) stock prices on exchange rates (pre-crisis) and (b) stock prices on exchange rates (post-crisis).

\begin{tabular}{|c|c|c|c|c|c|c|c|c|c|c|c|}
\hline \multicolumn{12}{|c|}{ (a) Stock Prices on Exchange Rates (Pre-Crisis) } \\
\hline \multirow[t]{2}{*}{ Country } & Variable & OLS & Bearish & Market & & Normal & Market & & Bullish & Market & \\
\hline & & & $\mathrm{Q}_{0.1}$ & $\mathrm{Q}_{0.2}$ & $\mathrm{Q}_{0.3}$ & $\mathrm{Q}_{0.4}$ & $\mathrm{Q}_{0.5}$ & $\mathrm{Q}_{0.6}$ & $\mathbf{Q}_{0.7}$ & $\mathrm{Q}_{0.8}$ & $Q_{0.9}$ \\
\hline \multirow[t]{2}{*}{ Cote d'Ivoire } & $B_{0}$ & 0.077 & $-1.488^{* * *}$ & $-0.987^{* * *}$ & $-0.590 * * *$ & $-0.270^{* * *}$ & -0.080 & $0.396^{* * *}$ & $0.804^{* * *}$ & $1.211^{* * *}$ & $1.724^{* * *}$ \\
\hline & $\beta_{1}$ & 0.017 & -0.022 & 0.010 & 0.026 & $0.043 * * *$ & 0.026 & 0.017 & 0.003 & -0.003 & -0.010 \\
\hline \multirow{2}{*}{ Ghana } & $\mathrm{B}_{0}$ & $-0.222 * *$ & $-2.228^{* * *}$ & $-0.822^{* * *}$ & $-0.398^{* * *}$ & $-0.170^{* * *}$ & $-0.057^{* *}$ & 0.000 & $0.152^{* * *}$ & $0.447^{* * *}$ & $1.412^{* * *}$ \\
\hline & $\beta_{1}$ & -0.054 & -0.054 & $-0.175^{* * *}$ & $-0.134^{* * *}$ & -0.057 & -0.018 & 0.000 & 0.021 & 0.081 & $0.172 * * *$ \\
\hline \multirow[t]{2}{*}{ Kenya } & $\beta_{0}$ & -0.004 & $-0.883^{* * *}$ & $-0.470 * * *$ & $-0.234^{* * *}$ & $-0.126^{* * *}$ & -0.004 & $0.102 * * *$ & $0.264^{* * *}$ & $0.515^{* * *}$ & $1.033^{* * *}$ \\
\hline & $\beta_{1}$ & $0.057^{* * *}$ & $0.075^{* * *}$ & 0.032 & 0.019 & $0.018^{*}$ & 0.013 & 0.011 & 0.007 & 0.004 & 0.052 \\
\hline \multirow[t]{2}{*}{ Mauritius } & $\beta_{0}$ & -0.012 & $-0.751^{* * *}$ & $-0.343^{* * *}$ & $-0.183^{* * *}$ & $-0.095^{* * *}$ & 0.000 & 0.000 ** & $0.085^{* * *}$ & $0.312 * * *$ & $0.712^{* * *}$ \\
\hline & $B_{1}$ & -0.034 & $-0.055^{*}$ & -0.042 & $-0.022 *$ & $-0.024 *$ & -0.000 & 0.00 & -0.016 & $-0.058 * * *$ & -0.039 \\
\hline \multirow[t]{2}{*}{ Nigeria } & $B_{0}$ & -0.011 & $-1.231^{* * *}$ & $-0.437^{* * *}$ & $-0.185^{* * *}$ & $-0.051 * *$ & 0.001 & $0.080^{* * *}$ & $0.228^{* * *}$ & $0.444^{* * *}$ & $0.910^{* * *}$ \\
\hline & $B_{1}$ & $-0.056^{* *}$ & $-0.089 * * *$ & $-0.044 * *$ & $-0.023^{* *}$ & -0.009 & -0.001 & -0.005 & $-0.024^{* *}$ & -0.027 & -0.015 \\
\hline \multicolumn{12}{|c|}{ (b)Stock Prices on Exchange Rates (Post-Crisis) } \\
\hline \multirow[t]{2}{*}{ Country } & Variable & OLS & Bearish & Market & & Normal & Market & & Bullish & Market & \\
\hline & & & $Q_{0.1}$ & $\mathrm{Q}_{0.2}$ & $\mathrm{Q}_{0.3}$ & $\mathrm{Q}_{0.4}$ & $\mathrm{Q}_{0.5}$ & $\mathrm{Q}_{0.6}$ & $\mathbf{Q}_{0.7}$ & $\mathbf{Q}_{0.8}$ & $Q_{0.9}$ \\
\hline \multirow[t]{2}{*}{ Cote d'Ivoire } & $\beta_{0}$ & -0.055 & $-1.676^{* * *}$ & $-1.014^{* * *}$ & $-0.651^{* * *}$ & $-0.322 * * *$ & -0.055 & $0.231^{* * *}$ & $0.579^{* * *}$ & $0.981^{* * *}$ & $1.526^{* * *}$ \\
\hline & $\beta_{1}$ & 0.039 & 0.046 & 0.035 & 0.017 & 0.013 & 0.039 & -0.002 & -0.040 & $-0.061 *$ & -0.092 * \\
\hline \multirow[t]{2}{*}{ Ghana } & $\beta_{0}$ & $-0.268^{* * *}$ & $-1.640 * * *$ & $-0.969^{* * *}$ & $-0.629 * * *$ & $-0.376^{* * *}$ & $-0.191^{* * *}$ & -0.062 & 0.047 & $0.381^{* * *}$ & $0.859^{* * *}$ \\
\hline & $\beta_{1}$ & 0.021 & $0.053^{* * *}$ & 0.027 & 0.012 & $0.019^{* *}$ & $0.014 *$ & 0.010 & 0.006 & -0.000 & -0.018 * \\
\hline \multirow[t]{2}{*}{ Kenya } & $\beta_{0}$ & $-0.064^{*}$ & $-0.888 * * *$ & $-0.431^{* * *}$ & $-0.237^{* * *}$ & $-0.152^{* * *}$ & -0.058 & $0.019 * * *$ & $0.143^{* * *}$ & $0.283^{* * *}$ & $0.677^{* * *}$ \\
\hline & $B_{1}$ & $0.084^{* * *}$ & $0.114^{* * *}$ & $0.076^{* * *}$ & 0.040 ** & 0.025 ** & $0.020^{* *}$ & 0.018 * & $0.026^{* *}$ & $0.038^{* *}$ & $0.071^{*}$ \\
\hline \multirow[t]{2}{*}{ Mauritius } & $\beta_{0}$ & -0.039 & $-1.146^{* * *}$ & $-0.648^{* * *}$ & $-0.347^{* * *}$ & $-0.155^{* * *}$ & 0.015 & $0.172 * * *$ & $0.351 * * *$ & $0.577^{* * *}$ & $1.014^{* * *}$ \\
\hline & $B_{1}$ & $0.058^{* *}$ & $0.064 * * *$ & $0.085^{* * *}$ & $0.101^{* * *}$ & $0.085^{*}$ & $0.105^{* * *}$ & $0.088^{*}$ & $0.091^{* *}$ & 0.069 & 0.071 \\
\hline \multirow[t]{2}{*}{ Nigeria } & $\beta_{0}$ & $-0.176^{* *}$ & $-0.953 * * *$ & $-0.425^{* * *}$ & $-0.203^{* * *}$ & $-0.075^{* * *}$ & -0.014 & 0.015 & $0.094^{* * *}$ & $0.260 * * *$ & $0.643^{* * *}$ \\
\hline & $B_{1}$ & 0.024 & $0.061^{* *}$ & $0.033^{* * *}$ & 0.013 & 0.009 & 0.004 & 0.005 & 0.006 & 0.018 & $0.030^{* * *}$ \\
\hline
\end{tabular}

Bearish $(\tau=0.10,0.20,0.30)$, normal $(\tau=0.40,0.50,0.60)$, bullish $(\tau=0.70,0.80,0.90)$. $\beta_{0}$ denotes constant, $B_{1}$ denotes coefficient of stock returns. $* * * * *$, and $*$ indicate statistical significance at $1 \%, 5 \%$, and $10 \%$ levels respectively.

In Table 12b, both OLS and QR showed that the effect of stock return on exchange rate was positive. Further, the QR model showed that the stock market had a significant effect on the exchange-rate market for all countries. However, the new results for Cote d'Ivoire differed from the previous findings, in that the stock return now significantly affected the exchange-rate market only in normal market conditions. For Nigeria, changes in stock prices affected the exchange rate only when the market was bullish, while in Ghana, the stock market led the exchange-rate market only when the market was bearish.

Regarding the effect of exchange rates on stock prices before the crisis, Table 13a shows that the effects were not significant for all countries except for Nigeria when the market was bullish, whereas the impact became significant for Mauritius (when the market was bullish) and Kenya (across all quantiles) after the crisis (Table 13b).

The effects of stock prices on exchange rates shown in Table 14a,b confirmed that the stock market had a significant effect on the exchange rates in the pre- and post-crisis periods. In the pre-crisis period, the QR showed that stock prices had a significant and negative effect on exchange rates when the market was bearish for all countries except for Cote d'Ivoire and Kenya. After the crisis, the effect of stock prices on exchange rates was significant for all countries; however, the effect was positive.

The results confirmed that the relationship between the two variables depended on the state of the market (bullish, normal, or bearish). We also showed that the stock-oriented model was more prevalent than the reverse effect; hence, we may conclude that our findings were robust.

\section{Conclusions}

In this study, we examined the dynamic relationship between FX and frontier markets for five sub-Saharan countries (Cote d'Ivoire, Ghana, Kenya, Mauritius, and Nigeria) using weekly data between January 2000 and December 2018. Although previous studies focused on this subject, none examined how changes in regime can impact the relationship between the FX and stock markets. This paper employs the MS-VAR model to that effect. We focused first on the MS-AR model to identify the regime-switching behaviour in the selected markets. Then, using MS-VAR, we explored the effect of regime changes on the relationship between the two variables. The MS-VAR model captured possible structural breaks and detected outliers in the data series. 
On the whole, our study revealed similar findings for both the stock and FX markets, as we observed that regime shifts occur frequently in both markets. However, the highvolatility regime was less persistent. This finding was contrary to the claim that frontier markets are highly volatile. The results from the smooth probability plots indicated that these markets were partially isolated from global shocks. Periods of high volatility appeared to be associated mostly with country-specific events, rather than global occurrences. Based on the results, we may cautiously infer that the frontier markets offer opportunities for portfolio diversification.

The results of the Markov-switching-VAR model provided evidence that the relationship between exchange rates and frontier markets was subject to regime changes. Additionally, these effects showed nonlinear characteristics, which implied that the MSVAR model was a good fit. However, Cote d'Ivoire seemed to be slightly different, as we observed no significant effect. Moreover, the results were not homogenous across countries in SSA; thus, the relationship between exchange rates and stock prices depended more on country-specific conditions. However, this does not change our main conclusion(s).

Overall, our findings are as follows: first, we provided evidence that the stock-oriented model played a more significant role than the flow-oriented model in SSA. The impact of exchange rates on stock prices was reduced and not significant in the low-volatility regime. Thus, we may infer that frontier markets are moderately segmented from exchange-rate changes, and hence are a safe haven for diversification for foreign investors. Second, we demonstrated that frontier markets provided positive returns in the high-volatility regime. This suggests that the frontier markets may be considered for hedging opportunities, as the downside risk appears to be low for all countries. Third, comovement for all countries was time-varying, suggesting that nonlinearities are an important issue to consider when analysing comovements in these countries.

\section{Implications/Policy Recommendations for the Countries Concerned}

In conclusion, our findings are of interest to investors, portfolio managers, and policymakers/advisors. First, the regime shifts in the relationship between stock and FX markets are of great significance in making portfolio allocations, as they help investors to further improve investment decisions by obtaining an understanding of the dynamic relationship between the two markets. It is recommended that investors consider the different regimes in both markets before they develop appropriate hedging strategies for risk diversification. Additionally, these countries are more prone to country-specific risk than global shocks, and may thus offer good hedging opportunities for investors when combined in a global portfolio.

The analysis indicated a significant impact from the stock market on the FX market; which has implications for stock-market policies. It is clear that a more robust and vibrant stock market in the sample countries could attract more foreign investors, which would in turn impact positively on their FX markets. As a recommendation, authorities of the respective countries must develop better strategies to bring about stability and increase depth in their stock markets in order to bring about desirable effects on the FX markets.

The positive effect of exchange rates on stock markets during a crisis means that domestic-currency depreciation will bring about a positive (negative) effect for export (import) firms and increase (decrease) their stock prices. Since these countries are relatively more import-dominant, depreciation of their currency is not favourable; therefore, policymakers should be mindful of the impact from FX markets to stock markets especially during a crisis. In particular, in making policy decisions, they will benefit from carefully examining the underlying forces behind the crisis. It is recommended that local governments take precautions against the potential risk factors to guard against potential spillovers and risk transmission between the FX and stock markets during future crises.

Finally, based on the nonsignificant effect in Cote d'Ivoire, we can cautiously deduce that to an extent, the restrictions on exchange-rate arrangements may reduce or mitigate the causality between exchange rates and stock prices in these countries. Thus, it is 
recommended that investors are mindful of the exchange-rate arrangements when making investment decisions.

Author Contributions: Data curation, M.K.; Formal analysis, E.G.; Funding acquisition, E.G.; Project administration, M.K.; Resources, E.G.; Supervision, E.G. All authors have read and agreed to the published version of the manuscript.

Funding: This research received no external funding.

Institutional Review Board Statement: Not applicable.

Informed Consent Statement: Not applicable.

Data Availability Statement: Data was downloaded from DataStream.

Conflicts of Interest: The authors declare no conflict of interest.

\section{References}

Adjasi, Charles, Simon K. Harvey, and Daniel Akwasi Agyapong. 2008. Effect of Exchange Rate Volatility on the Ghana Stock Exchange. African Journal of Accounting, Economics, Finance and Banking Research 3: 28-47.

Adjasi, Charles K., Nicholas B. Biekpe, and Kofi A. Osei. 2011. Stock prices and exchange rate dynamics in selected African countries: A bivariate analysis. African Journal of Economic and Management Studies 2: 143-64. [CrossRef]

AfDB, OECD, and UNDP. 2015. African Economic Outlook 2015: Regional Development and Spatial Inclusion. Available online: https://www.oecd-ilibrary.org/development/african-economic-outlook-2015_aeo-2015-en (accessed on 1 October 2018).

Ahmad, Wasim, and Sanjay Sehgal. 2015. Regime shifts and volatility in BRICS stock markets: An asset allocation perspective. International Journal of Emerging Markets 10: 383-408. [CrossRef]

Akram, Q. Farooq. 2004. Oil prices and exchange rates: Norwegian evidence. The Econometrics Journal 7: 476-504. [CrossRef]

Ang, Andrew, and Geert Bekaert. 2002. International asset allocation with regime shifts. The Review of Financial Studies 15: 1137-87. [CrossRef]

Bahmani-Oskooee, Mohsen, and Sujata Saha. 2015. On the relation between stock prices and exchange rates: A review article. Journal of Economic Studies 42: 707-32. [CrossRef]

Bai, Jushan, and Pierre Perron. 1998. Estimating and testing linear models with multiple structural changes. Econometrica, 47-78. [CrossRef]

Bailliu, Jeannine, and Michael R. King. 2005. What Drives Movements in Exchange Rates? Bank of Canada Review 2005: 27-39.

Balcilar, Mehmet, Rangan Gupta, and Stephen M. Miller. 2015. Regime switching model of US crude oil and stock market prices: 1859 to 2013. Energy Economics 49: 317-27. [CrossRef]

Beck, Thorsten, Samuel Munzele Maimbo, Issa Faye, and Thouraya Triki. 2011. Financing Africa: Through the Crisis and Beyond. Washington, DC: The World Bank.

Berger, Theo, and Gazi Salah Uddin. 2016. On the dynamic dependence between equity markets, commodity futures and economic uncertainty indexes. Energy Economics 56: 374-83. [CrossRef]

Bergman, U. Michael, and Jesper Hansson. 2005. Real exchange rates and switching regimes. Journal of International Money and Finance 24: 121-38. [CrossRef]

Bleaney, Michael, and David Greenaway. 2001. The impact of terms of trade and real exchange rate volatility on investment and growth in sub-Saharan Africa. Journal of Development Economics 65: 491-500. [CrossRef]

Bloomberg, L.P. 2019. Bloomberg. Available online: https://www.bloomberg.com/press-releases/2019-09-10/annual-report-2019 (accessed on 1 December 2019).

Box, George, and Gwilym Jenkins. 1976. Time Series Analysis, Forecasting and Control. San Francisco: Holden-Day.

Branson, William H. 1983. Macroeconomic determinants of real exchange rate risk. In Managing Foreign Exchange Rate Risk. Edited by Ronald J. Herring. Cambridge: Cambridge University Press.

Broock, William A., Jose Alexandre Scheinkman, W. Davis Dechert, and Blake LeBaron. 1996. A test for independence based on the correlation dimension. Econometric Reviews 15: 197-235. [CrossRef]

Cai, Jun. 1994. A Markov model of switching-regime ARCH. Journal of Business and Economic Statistics 12: 309-16.

Caporale, Guglielmo Maria, John Hunter, and Faek Menla Ali. 2014. On the linkages between stock prices and exchange rates: Evidence from the banking crisis of 2007-2010. International Review of Financial Analysis 33: 87-103. [CrossRef]

Chen, Long, and Xinlei Zhao. 2009. Return decomposition. The Review of Financial Studies 22: 5213-49. [CrossRef]

Chiang, Thomas C., Bang Nam Jeon, and Huimin Li. 2007. Dynamic correlation analysis of financial contagion: Evidence from Asian markets. Journal of International Money and Finance 26: 1206-28. [CrossRef]

Chkili, Walid, and Duc Khong Nguyen. 2014. Exchange rate movements and stock market returns in a regime-switching environment: Evidence for BRICS countries. Research in International Business and Finance 31: 46-56. [CrossRef]

Chortareas, Georgios, Andrea Cipollini, and Mohamed Abdelaziz Eissa. 2011. Exchange rates and stock prices in the MENA countries: What role for oil? Review of Development Economics 15: 758-74. [CrossRef] 
Chow, Edward H., Wayne Y. Lee, and Michael E. Solt. 1997. The exchange-rate risk exposure of asset returns. Journal of Business, 105-23. Available online: https:/ / www.jstor.org/stable/2353483 (accessed on 1 November 2018). [CrossRef]

Davies, Robert. B. 1987. Hypothesis testing when a nuisance parameter is present only under the alternative. Biometrika 74: 33-43.

Dickey, David A., and Wayne A. Fuller. 1979. Distribution of the estimators for autoregressive time series with a unit root. Journal of the American Statistical Association 74: 427-31.

Diebold, Francis X., and Kamil Yilmaz. 2009. Measuring financial asset return and volatility spillovers, with application to global equity markets. The Economic Journal 119: 158-71. [CrossRef]

Dornbusch, Rudiger, and Stanley Fischer. 1980. Exchange rates and the current account. The American Economic Review 70: 960-71.

Eissa, Mohamed Abdelaziz, Georgios Chortareas, and Andrea Cipollini. 2010. Stock returns and exchange rate volatility spillovers in the MENA region. Journal of Emerging Market Finance 9: 257-84. [CrossRef]

Engel, Charles. 1994. Can the Markov Switching model forecast exchange rates? Journal of International Economics 36: 151-65. [CrossRef]

Engle, Charles, and James D. Hamilton. 1990. Long swings in the dollar: Are they in the data and do markets know it. American Economic Review 80: 689-713.

Forbes, Kristin J., and Roberto Rigobon. 2002. No contagion, only interdependence: Measuring stock market comovements. The Journal of Finance 57: 2223-61. [CrossRef]

FTSE Russell. 2014. Frontier Markets: Accessing the Next Frontier. Available online: https://www.ftse.com/products/downloads / FTSE_Frontier_Markets_Overview.pdf (accessed on 1 November 2018).

Gallo, Giampiero M., and Edoardo Otranto. 2008. Volatility spillovers, interdependence and comovements: A Markov Switching approach. Computational Statistics \& Data Analysis 52: 3011-26.

Garcia, Rene, and Pierre Perron. 1996. An analysis of the real interest rate under regime shifts. Review of Economics and Statistics 78: 111-25. [CrossRef]

Hamilton, James D. 1989. A new approach to the economic analysis of nonstationary time series and the business cycle. Econometrica: Journal of the Econometric Society, 357-84. [CrossRef]

Hatemi-J, Abdulnasser, and Manuchehr Irandoust. 2002. On the causality between exchange rates and stock prices: A note. Bulletin of Economic Research 54: 197-203. [CrossRef]

Hess, Martin K. 2002. What drives Markov regime-switching behaviour of stock markets? The Swiss Case. International Review of Financial Analysis 12: 527-43. [CrossRef]

Hwang, Jae-Kwang. 1999. The relationship between stock prices and exchange rates: Evidence from Canada. International Advances in Economic Research 5: 397. [CrossRef]

Ilzetzki, Ethan, Carmen M. Reinhart, and Kenneth S. Rogoff. 2017. The Country Chronologies to Exchange Rate Arrangements into the 21st Century: Will the Anchor Currency Hold? (No. w23135). Cambridge: National Bureau of Economic Research.

IMF. 2016. Exchange Rate Regimes in Sub-Saharan Africa: Experiences and Lessons. Available online: https://www.imf.org/ \{\}\} media/Websites/IMF/imported-flagshipissues/external/pubs/ft/reo/2016/afr/eng/pdf/_chapter21016pdf.ashx (accessed on 1 October 2018).

Ismail, Mohd Tahir, and Zaidi Isa. 2007. Detecting regime shifts in Malaysian exchange rates. Malaysian Journal of Fundamental and Applied Sciences 3: 211-24. [CrossRef]

Ismail, Mohd Tahir, and Zaidi Isa. 2008. Identifying regime shifts in Malaysian stock market returns. International Research Journal of Finance and Economics 15: 44-57.

Johansen, Soren, and Katarina Juselius. 1990. Maximum likelihood estimation and inference on cointegration with applications to the demand for money. Oxford Bulletin of Economics and Statistics 52: 169-210. [CrossRef]

Kanas, Angelos. 2000. Volatility spillovers between stock returns and exchange rate changes: International evidence. Journal of Business Finance and Accounting 27: 447-67. [CrossRef]

Kanas, Angelos. 2002. Is exchange rate volatility influenced by stock return volatility? Evidence from the US, the UK and Japan. Applied Economics Letters 9: 501-3. [CrossRef]

Kanas, Angelos. 2005. Regime linkages between the Mexican currency market and emerging equity markets. Economic Modelling 22: 109-25. [CrossRef]

Kodongo, Odongo, and Kalu Ojah. 2011. Foreign exchange risk pricing and equity market segmentation in Africa. Journal of Banking $\mathcal{E}$ Finance 35: 2295-310.

Krolzig, Hans-Martin. 2001. Markov-Switching Vector Autoregressions: Modelling, Statistical Inference, and Application to Business Cycle Analysis. Berlin and Heidelberg: Springer Science \& Business Media, vol. 454.

Kutty, Gopolan. 2010. The relationship between exchange rates and stock prices: The case of Mexico. North American Journal of Finance and Banking Research 4: 1-12.

Kwiatkowski, Denis, Peter C.B. Phillips, Peter Schmidt, and Yongcheol Shin. 1992. Testing the null hypothesis of stationarity against the alternative of a unit root: How sure are we that economic time series have a unit root? Journal of Econometrics 54: 159-78. [CrossRef]

Lee, Chia-Hao, Shuh-Chyi Doong, and Pei-I. Chou. 2011. Dynamic correlation between stock prices and exchange rates. Applied Financial Economics 21: 789-800. [CrossRef]

Li, Huimin, and Thomas C. Chiang. 2017. Regime Switching on the Relationship between Stock Returns and Currency Values: Evidence from the 1997 Asian Crisis. In Handbook of Investors' Behavior During Financial Crises. Cambridge: Academic Press, pp. $257-76$. 
Lim, Sung, and Evangelos Giouvris. 2015. Liquidity volatility and spillover effects: Evidence from the UK-USA and East Asian countries. International Journal of Financial Engineering and Risk Management 2: 48-71. [CrossRef]

Liu, Xinyi, Dimitris Margaritis, and Peiming Wang. 2012. Stock market volatility and equity returns: Evidence from two-state Markov-switching model with regressors. Journal of Empirical Finance 19: 483-96. [CrossRef]

Lv, Xin, Donald Lien, Qian Chen, and Chang Yu. 2018. Does exchange rate management affect the causality between exchange rates and oil prices? Evidence from oil-exporting countries. Energy Economics 76: 325-43. [CrossRef]

Ma, Christopher K., and G. Wenchi Kao. 1990. On exchange rate changes and stock price reactions. Journal of Business Finance $\mathcal{E}$ Accounting 17: 441-49.

MacKinnon, James G., Alfred A. Haug, and Leo Michelis. 1999. Numerical distribution functions of likelihood ratio tests for cointegration. Journal of Applied Econometrics 14: 563-77. [CrossRef]

Migiakis, Petros M., and Fivos V. Bekiris. 2009. Regime switches between dividend and bond yields. International Review of Financial Analysis 18: 198-204. [CrossRef]

Ntim, Collins G. 2012. Why African stock markets should formally harmonise and integrate their operations. African Review of Economics and Finance 4: 53-72.

Pan, Ming-Shiun, Robert Chi-Wing Fok, and Y. Angela Liu. 2007. Dynamic linkages between exchange rates and stock prices: Evidence from East Asian markets. International Review of Economics and Finance 16: 503-20. [CrossRef]

Parikakis, George S., and Anna Merika. 2009. Evaluating volatility dynamics and the forecasting ability of Markov switching models. Journal of Forecasting 28: 736-44. [CrossRef]

Pericoli, Marcello, and Massimo Sbracia. 2003. A primer on financial contagion. Journal of Economic Surveys 17: 571-608. [CrossRef]

Phillips, Peter C., and Pierre Perron. 1988. Testing for a unit root in time series regression. Biometrika 75: 335-46. [CrossRef]

Phylaktis, Kate, and Fabiola Ravazzolo. 2005. Stock prices and exchange rate dynamics. Journal of International Money and Finance 24: 1031-53. [CrossRef]

Roll, Richard. 1992. Industrial structure and the comparative behavior of international stock market indices. The Journal of Finance 47: 3-41. [CrossRef]

Roubaud, David, and Mohamed Arouri. 2018. Oil prices, exchange rates and stock markets under uncertainty and regime-switching. Finance Research Letters 27: 28-33. [CrossRef]

Sarno, Lucio, and Giorgio Valente. 2006. Deviations from purchasing power parity under different exchange rate regimes: Do they revert and, if so, how? Journal of Banking \& Finance 30: 3147-69.

SEC. 2017. Securities and Exchange Commission Ghana, Annual Report. Available online: http://sec.gov.gh/wp-content/uploads/ Annual-Reports /2017-Annual-Report.pdf (accessed on 1 May 2020).

Smyth, Russell, and Mohan Nandha. 2003. Bivariate causality between exchange rates and stock prices in South Asia. Applied Economics Letters 10: 699-704. [CrossRef]

Sugimoto, Kimiko, Takashi Matsuki, and Yushi Yoshida. 2014. The global financial crisis: An analysis of the spillover effects on African stock markets. Emerging Markets Review 21: 201-33. [CrossRef]

Tsagkanos, Athanasios, and Costas Siriopoulos. 2013. A long-run relationship between stock price index and exchange rate: A structural nonparametric cointegrating regression approach. Journal of International Financial Markets, Institutions and Money 25: 106-18. [CrossRef]

Tsai, I-Chun. 2012. The relationship between stock price index and exchange rate in Asian markets: A quantile regression approach. Journal of International Financial Markets, Institutions and Money 22: 609-21. [CrossRef]

Tsai, Chun-Li. 2015. How do US stock returns respond differently to oil price shocks pre-crisis, within the financial crisis, and post-crisis? Energy Economics 50: 47-62. [CrossRef]

Tule, Moses, Mela Dogo, and Godfrey Uzonwanne. 2018. Volatility of stock market returns and the naira exchange rate. Global Finance Journal 35: 97-105. [CrossRef]

Walid, Chkili, Aloui Chaker, Omar Masood, and John Fry. 2011. Stock market volatility and exchange rates in emerging countries: A Markov-state switching approach. Emerging Markets Review 12: 272-92. [CrossRef]

Wang, Ping, and Mike Theobald. 2008. Regime-switching volatility of six East Asian emerging markets. Research in International Business and Finance 22: 267-83. [CrossRef]

Wang, Yi-Chiuan, Jyh-Lin Wu, and Yi-Hao Lai. 2013. A revisit to the dependence structure between the stock and foreign exchange markets: A dependence-switching copula approach. Journal of Banking \& Finance 37: 1706-19.

World Bank. 2010. Global Economic Prospects 2010: Crisis, Finance and Growth. Available online: https:/ / elibrary.worldbank.org/ doi/abs/10.1596/978-0-8213-8226-4 (accessed on 1 November 2018). 